Research Article

\title{
Experimental and Numerical Investigation on Dynamic Properties and Human-Induced Vibrations of an Asymmetric Steel-Plated Stress-Ribbon Footbridge
}

\author{
Yi Zhang ${ }^{1 D},{ }^{1}$ Wei He ${ }^{(D},{ }^{2}$ Jiewen Zhang ${ }^{D},{ }^{2}$ and Hua Dong $\mathbb{D}^{1}$ \\ ${ }^{1}$ China Construction Third Bureau First Engineering Co., LTD., Wuhan 430080, Hubei, China \\ ${ }^{2}$ Faculty of Engineering, China University of Geosciences, Wuhan 430074, Hubei, China \\ Correspondence should be addressed to Hua Dong; donghua606@163.com
}

Received 3 October 2021; Accepted 13 November 2021; Published 22 December 2021

Academic Editor: Lingkun Chen

Copyright (c) 2021 Yi Zhang et al. This is an open access article distributed under the Creative Commons Attribution License, which permits unrestricted use, distribution, and reproduction in any medium, provided the original work is properly cited.

\begin{abstract}
This paper presents a comprehensive study on dynamic properties and human-induced vibrations of a slender asymmetric steelplated stress-ribbon footbridge via both experimental and analytical methods. Bridge modal test was conducted using both ambient vibration testing and impact methods. Modal properties of the bridge were identified based on stochastic subspace identification and peak-pick techniques. Results show that the bridge is characterized by closely spaced modes with low natural frequencies and small damping ratios $(<0.002)$. A sophisticated finite element model that incorporates pretension of the stress ribbon and contribution of deck panels is developed and proven to be capable of reflecting the main dynamic characteristics of the bridge. Human-induced vibrations were measured considering synchronization cases, including single-person and small group walking as well as random walking cases. A theoretical model that takes into account human-structure interaction was developed, treating the single walking person as an SDOF system with biomechanical excited force. The validity of the model was further verified by measurement results.
\end{abstract}

\section{Introduction}

Structures are prone to have longer spans and become much flexible owing to the development of high strength and lightweight materials and innovation in construction methods [1]. This poses new challenges to structural design since slender structures are more susceptible to dynamic loadings such as human excitation or wind turbulence.

Many efforts have been made on human-induced vibrations of footbridges [1-12], long-span floors [13-16], and stadiums $[17,18]$. These researches cover the aspect of human-induced load models (either deterministic [1] or stochastic [2-6]), human-structure interaction [7-9], vibration serviceability evaluation method [12-18], and vibration control countermeasures [10-12].

In recent years, the stress-ribbon footbridge has been increasingly preferred due to its elegant and simple shape, fewer components compared with traditional footbridges, and low impact on surroundings [19-24]. Stress-ribbon footbridge, always formed by pretension catenary-shaped cables or steel plates with both ends anchored on the abutments, are characterized by closely spaced modes with low natural frequencies $[19,23,24]$. Hence, their dynamic performance under human excitation is often of great concern. A modal test is the most accurate and effective way to obtain the actual dynamic properties of the structure. In this regard, Hu et al. [23] tested a stress-ribbon footbridge in a campus in Portugal, which has two close spans of $30 \mathrm{~m}$ and $28 \mathrm{~m}$. The bridge is formed by four pretensioned catenaryshaped cables embedded by a continuous concrete cast-insitu slab. A modal test showed that the footbridge has low natural frequencies and closely spaced modes. The first eight natural frequencies are all below $6 \mathrm{~Hz}$. Specifically, the first three natural frequencies are $0.951 \mathrm{~Hz}, 1.989 \mathrm{~Hz}$, and $2.034 \mathrm{~Hz}$, respectively. Soria et al. [24] reported a steel-plated stress-ribbon footbridge constructed in 2009 in Spain. The 
bridge employs a singular catenary-shaped steel band with a single span of $85 \mathrm{~m}$. A modal test reveals that the footbridge is so flexible and lightly damped. The modes are closely spaced with the first eight natural frequencies that are all less than $4 \mathrm{~Hz}$. Specifically, the first three natural frequencies are $0.867 \mathrm{~Hz}, 1.408 \mathrm{~Hz}$, and $1.541 \mathrm{~Hz}$. The identified first eight damping ratios range from $0.3 \%$ to $0.6 \%$. All these researches demonstrated that the stress-ribbon bridges are susceptible to dynamic excitation, and their dynamic performance needs careful evaluation. Arndt et al. [22] pointed out that stress-ribbon footbridges are the most slender and flexible structures. To date, application cases of stress-ribbon bridges or footbridges are still limited. The relevant experimental work, especially the dynamic performance under walking people, is rarely reported.

This paper reports a newly built slender asymmetric steel-plated stress-ribbon footbridge in China, where the stress ribbon is fabricated using the Chinese Q690D steel plate. This is the first time that the Q690D steel plate has been used in a real footbridge in China. The contribution of this study is twofold. On the one hand, this paper presents a comprehensive study of the footbridge's modal properties and dynamic performance under human excitation through combined experimental and analytical methods, which has rarely been reported before. On the other hand, it is beneficial to enrich the current experimental database of stressribbon footbridges. It would also be helpful for the future mechanical analysis and design of similar structures.

The paper is structured as follows: The concerned footbridge was briefly introduced in Section 2, followed by a modal test program in Section 3. Section 4 develops a detailed finite element model to capture the main dynamic characteristics of the footbridge. Section 5 gives the experimental results of human-induced vibrations, including synchronized walking and random walking cases. A theoretical model that takes into account moving humanstructure interaction is developed in Section 6. Some conclusions are given in the closing Section 7.

\section{Outline of the Test Footbridge}

The stress-ribbon footbridge (see Figure 1(a)), constructed in 2020 and located in a park in Shenzhen, China, is a slender footbridge that links two mountains as part of a greenway. The bridge is an asymmetric stress-ribbon footbridge formed by a pretensioned catenary-shaped steel band with a main span of $63.8 \mathrm{~m}$ and a side span of $24.2 \mathrm{~m}$. The net width of the bridge deck is $2.3 \mathrm{~m}$, allowing for two-way pedestrian traffic. The top deck is $30 \mathrm{~m}$ above the bottom of the valley. The cross section of the bridge consists of two main stress-ribbon plates made of Chinese Q690D steel with a thickness of $40 \mathrm{~mm}$ and width of $750 \mathrm{~mm}$ at a spacing of $0.4 \mathrm{~m}$, as shown in Figures 1(b) and 1(c). Both ends of the stress ribbons are anchored on the abutments. Precast concrete panels with dimensions of $2.7 \mathrm{~m}$ in length, $0.855 \mathrm{~m}$ in width, and $0.12 \mathrm{~m}$ in thickness were evenly paved on the stress ribbons along the longitudinal direction of the bridge (see Figures 1(c) and $1(\mathrm{~d}))$. The space between two incident concrete panels is $0.02 \mathrm{~m}$. Shear keys are evenly placed on top of the stress ribbon to keep a reliable connection between the precast concrete panels and the main structure. The stress ribbon and deck panels are supported by a bracket comprising two inclined steel tube columns with variable cross-sections, as shown in Figure 1(e). The two columns are transversally braced by three horizontal steel pipes and three pairs of diagonal cables (see Figure 1(e)). Handrails made of stainless steel net with a height of $1.15 \mathrm{~m}$ are erected on both sides of the bridge deck (see Figure 1(d)). The abutments were cast in artificial digging piles using concrete and prestressed anchor cables.

\section{Modal Test of the Stress-Ribbon Footbridge}

3.1. Test Setup. A modal test was conducted to obtain the dynamic properties of the footbridge based on the ambient vibration testing (AVT) method $[25,26]$. The bridge deck was divided into 30 grids along the longitudinal direction. 58 test points (TPs) were evenly spaced at an interval of $3 \mathrm{~m}$ on both sides of the bridge to obtain the spatial mode shapes, i.e., 29 at each side, as shown in Figure 2. The test program was divided into ten groups due to the limited number of accelerometers and cable length. TP 21, located near the east side of the main span, was chosen as the fixed reference point, while the other TPs were movable points. The classification of the setup of TPs is listed in Table 1. All accelerometers are in the vertical direction, and the bridge lateral modes were not considered due to the availability of test time. During the test, the bridge was temporally closed to avoid the effect of pedestrians.

Accelerometers with the nominate frequency range from $0.25 \mathrm{~Hz}$ to $100 \mathrm{~Hz}$ and a measurement capacity of $2 \mathrm{~g}$ ( $g$ is gravitational acceleration) were adopted. The DH9581 vibration data acquisition system, produced by Donghua company, China, was used for data recording. The sampling frequency was $200 \mathrm{~Hz}$, which can cover the most concerned frequencies of the bridge. Figure 3 gives the photographs of the modal test.

For each setup, accelerometers were well fixed on the bridge deck according to the test protocol. A duration of $10 \mathrm{~min}$ was recorded for each setup. The test procedure is shown in Figure 4.

3.2. Test Results. Figure 5 illustrates part of the deck acceleration at the reference point (TP 21) under AVT. It is evident that the bridge deck was in small amplitude, and the vibration generally kept steady in the ambient vibration environment.

Figure 6 further gives the frequency spectrum below $6 \mathrm{~Hz}$. Specifically, as shown in Figure 6(a), the test bridge has closely spaced modes with most natural frequencies below $4 \mathrm{~Hz}$. Figures $6(\mathrm{~b}) \sim 6(\mathrm{~d})$ show the zoom-in view for the first three dominant frequencies at all test points. The measured first three natural frequencies are $0.95 \mathrm{~Hz}, 1.45 \mathrm{~Hz}$, and $1.68 \mathrm{~Hz}$, respectively.

Meanwhile, the first three natural frequencies and corresponding mode shapes and damping ratios were identified 


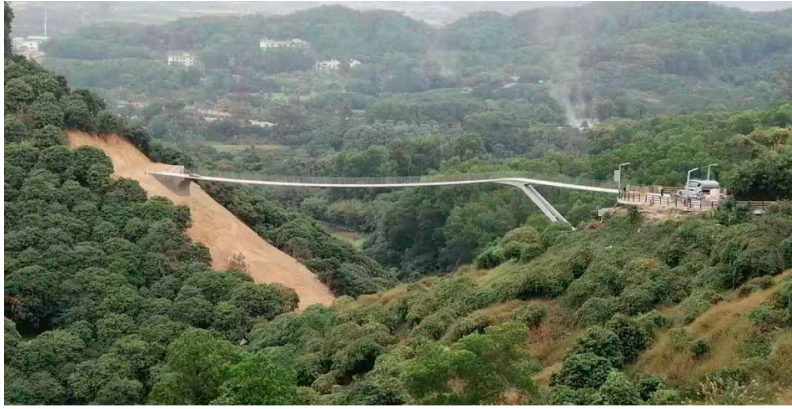

(a)

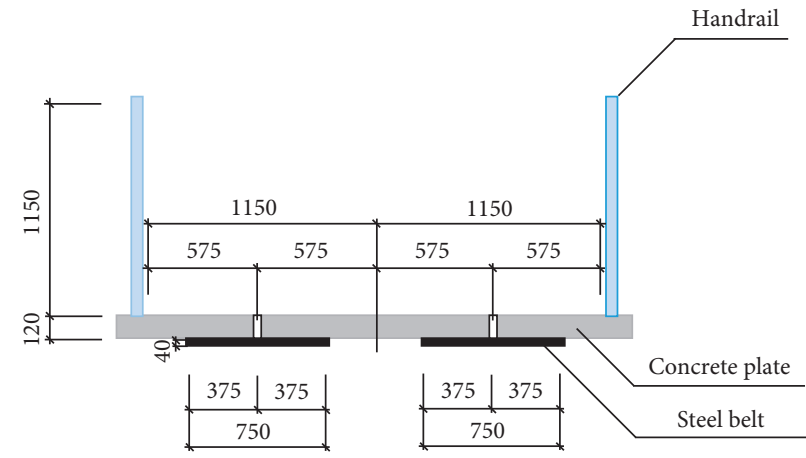

(c)

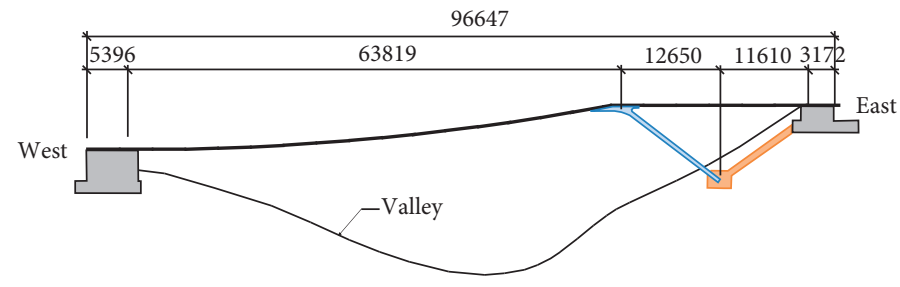

(b)

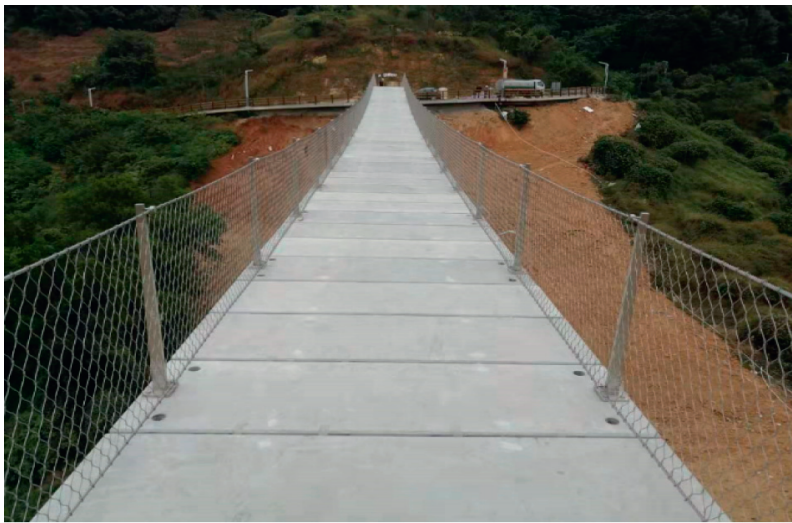

(d)

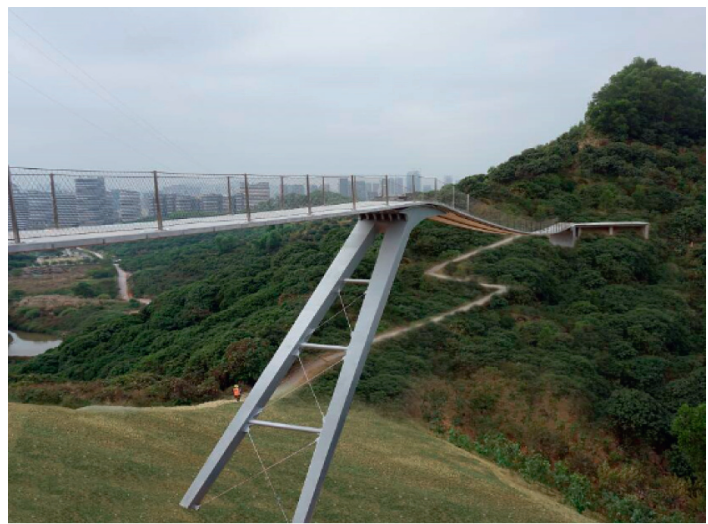

(e)

Figure 1: Schematic view and real pictures of the test bridge. (a) Real photograph, (b) elevation, (c) cross section, (d) bridge deck, and (e) columns. All dimensions are in $\mathrm{mm}$.

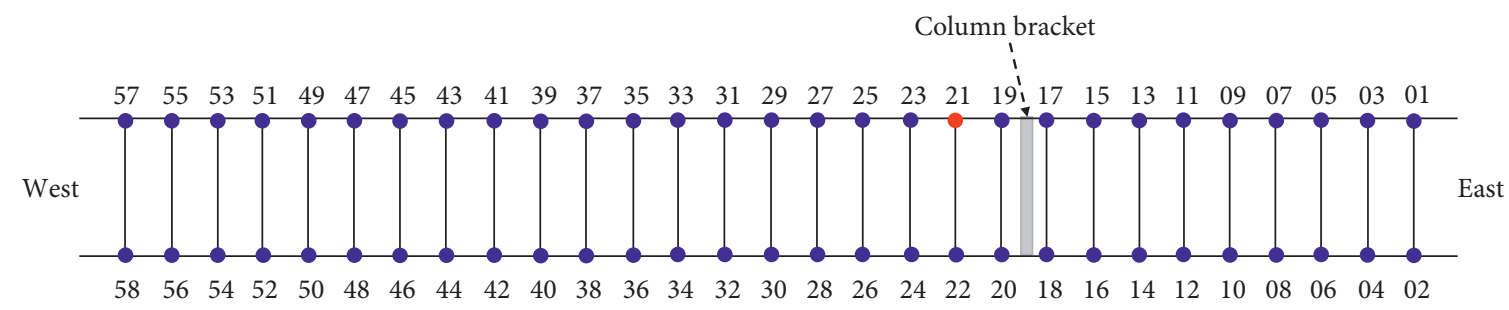

FIgURE 2: Schematic diagram of measurement grid. TP 21 in red is the reference point.

based on the stochastic subspace identification (SSI) method [27-30], given in Table 2. Figure 7 shows the first three mode shapes. Specifically, the first mode is a typical vertical bending mode of the main span, the second mode is also a vertical bending mode, and the third mode corresponds to the first bending mode of the side span. 
TABle 1: Setup of measurement points.

\begin{tabular}{lcr}
\hline Set number & Test point number & Reference point \\
\hline 1 & $07,08,09,10,11,12,13,57,58$ & 21 \\
2 & $14,15,16,17,18,19,20,55,56$ & 21 \\
3 & $01,02,03,04,05,06,53,54$ & 21 \\
4 & $22,23,24,25,26,27,28,51,52$ & 21 \\
5 & $29,30,31,32,33,34,35,49,50$ & 21 \\
6 & $36,37,38$ & 21 \\
7 & $39,43,44$ & 21 \\
8 & $40,41,42$ & 21 \\
9 & $45,46,47$ & 21 \\
10 & 48 & 21 \\
\hline
\end{tabular}

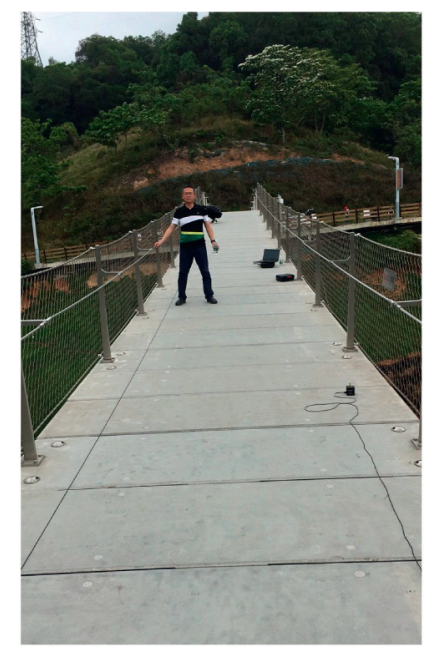

(a)

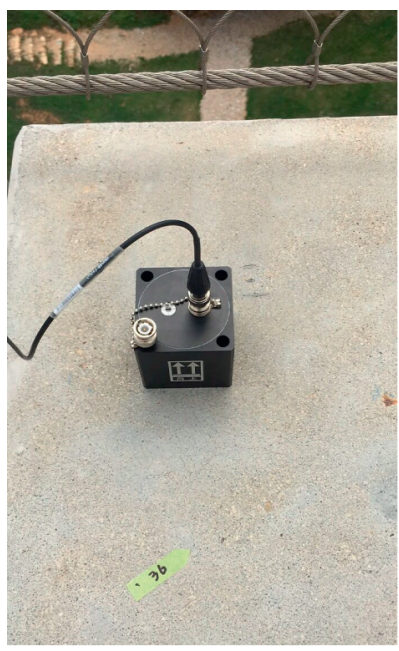

(b)

Figure 3: Photographs of the modal test. (a) Test scenario and (b) accelerometer.

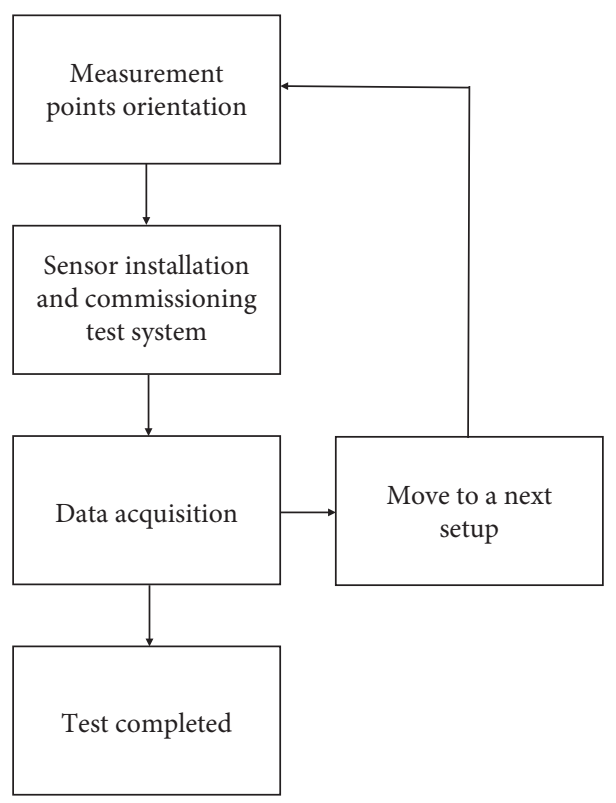

Figure 4: Flow chart of the test protocol. 


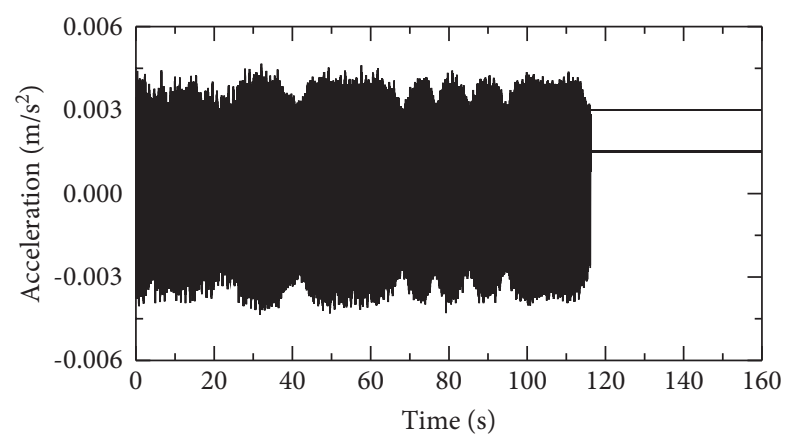

FiguRE 5: Bridge acceleration at reference point 23 under ambient vibration.

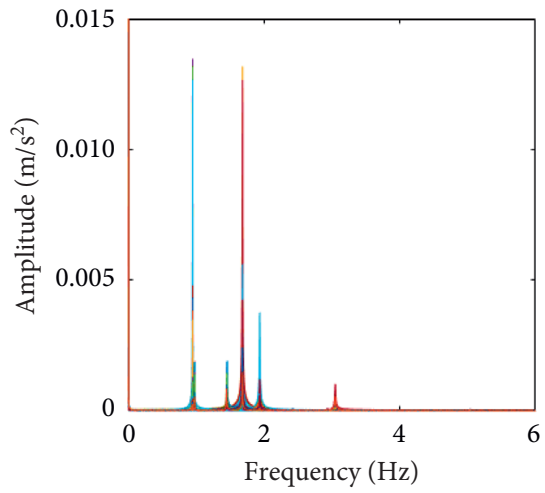

(a)

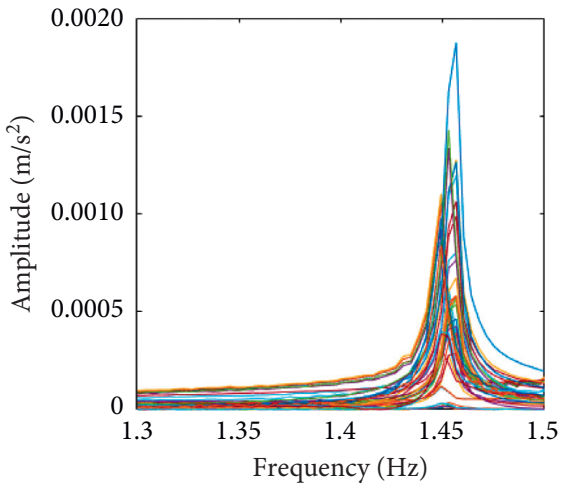

(c)

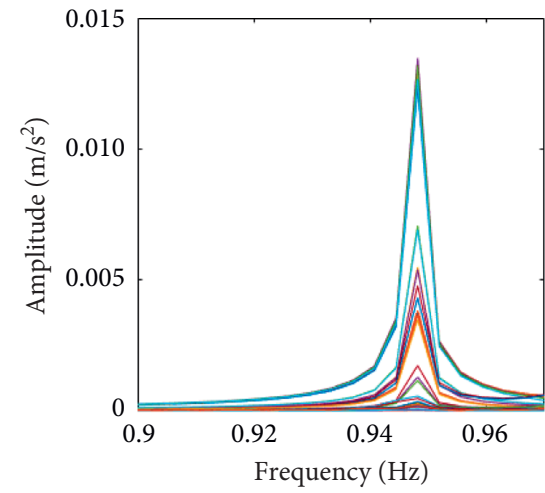

(b)

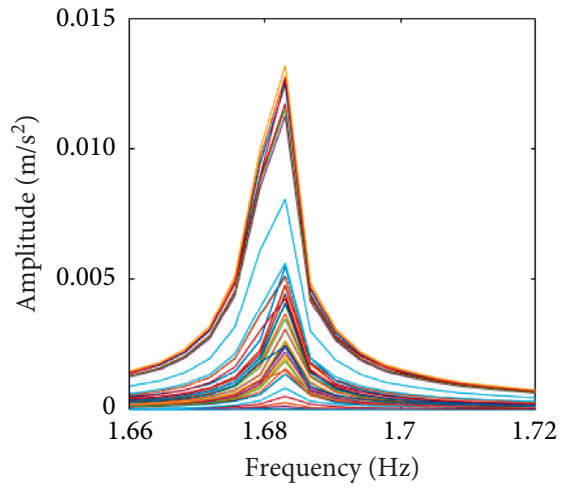

(d)

FIGURE 6: Frequency spectrum of the bridge: (a) overall view and (b-d) enlarged view.

TABle 2: First three identified dynamic characteristics of the bridge.

\begin{tabular}{|c|c|c|c|c|c|}
\hline \multirow{2}{*}{ Mode no. } & \multicolumn{2}{|c|}{ Frequency $(\mathrm{Hz})$} & \multicolumn{2}{|c|}{ Damping ratio } & \multirow{2}{*}{ Modal description } \\
\hline & SSI & $\mathrm{PP}$ & SSI & PP & \\
\hline 1 & 0.95 & 0.95 & 0.0014 & 0.0018 & $1^{\text {st }}$ vertical bending \\
\hline 2 & 1.45 & 1.45 & 0.0020 & 0.0017 & $2^{\text {nd }}$ vertical bending \\
\hline 3 & 1.68 & 1.68 & 0.0006 & 0.0009 & $3^{\text {rd }}$ vertical bending \\
\hline
\end{tabular}

Note. SSI: stochastic subspace identification; PP: peak-picking.

A heel impact test was also conducted to check the accuracy of the identified results by the SSI method. The details of the heel-drop impact method can be found in
$[8,25]$. The free decay time history of the bridge deck was truncated from the entire vibration record. Figure 8(a) shows the free decay response of the bridge deck, and 


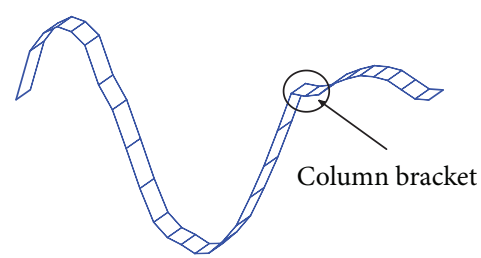

(a)

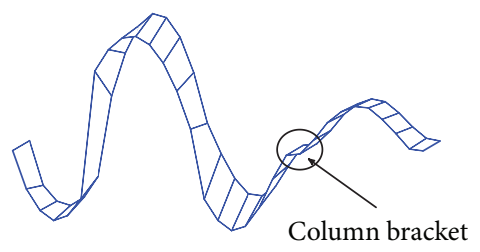

(b)

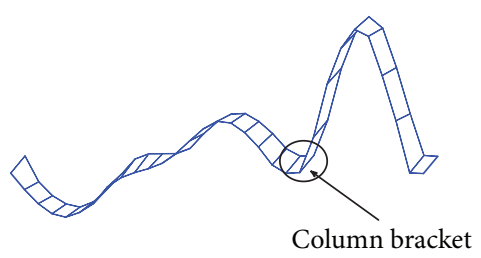

(c)

FiguRe 7: First three modes of the bridge. (a) $1^{\text {st }}$ vertical bending, $f_{v, 1}=0.95 \mathrm{~Hz}$. (b) $2^{\text {nd }}$ vertical bending, $f_{v, 2}=1.45 \mathrm{~Hz}$. (c) $3^{\text {rd }}$ bending, $f_{v, 3}=1.68 \mathrm{~Hz}$.

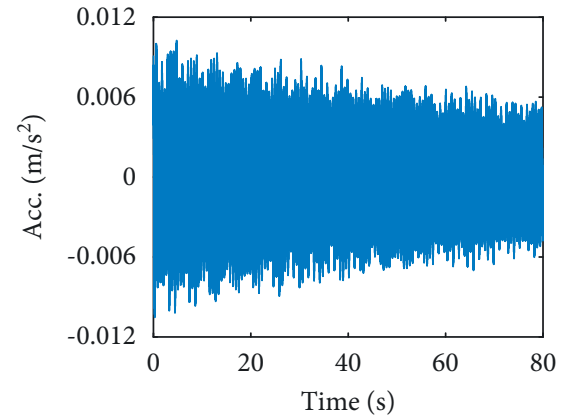

(a)

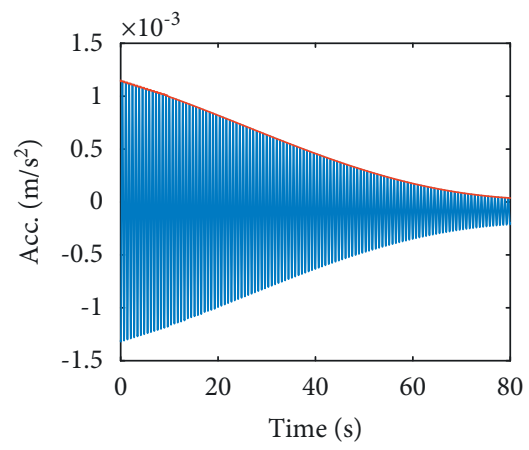

(c)

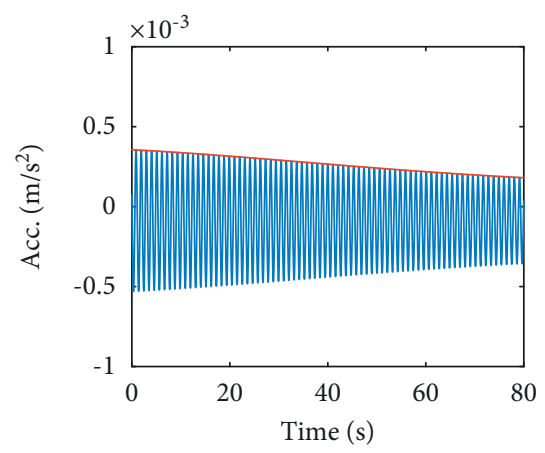

(b)

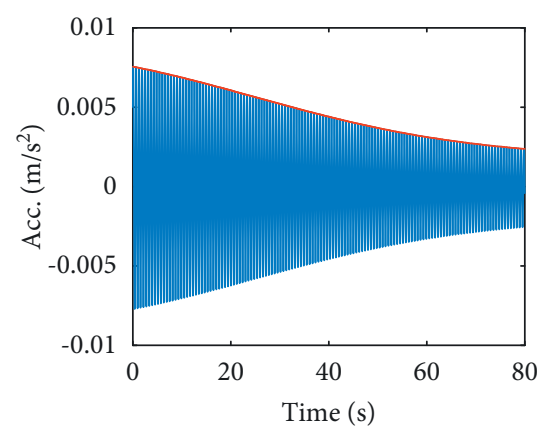

(d)

Figure 8: Free decay response of the bridge. (a) Overall response, (b) $0.8 \sim 0.96 \mathrm{~Hz}$, (c) $1.4 \sim 1.5 \mathrm{~Hz}$, and (d) $1.58 \sim 1.78 \mathrm{~Hz}$.

Figures $8(\mathrm{~b})-8$ (d) further give the filtering result using the fifth Butterworth filter with cut-off frequencies at $0.8 \sim 0.96 \mathrm{~Hz}, 1.4 \sim 1.5 \mathrm{~Hz}$, and $1.58 \sim 1.78 \mathrm{~Hz}$. Each individual component generally decreases in a free decay manner with a single vibration frequency. The corresponding spectrum of each individual is not presented here to keep the paper concise. As shown in Figures 8(b) to 8(d), each component can be regarded as a damped single-degree-of-freedom (SDOF) system.

For a damped SDOF, various damping estimation methods, such as the logarithmic decrement method and half-power spectrum methods $[25,30]$, could be employed to estimate the modal damping ratio. In this paper, the damping ratio was estimated using the ratio of the adjacent area formed by the free decay time series and the time axis, expressed as [31]

$$
\xi=\frac{1}{2 \pi} \ln \frac{S_{i}}{S_{i+1}},
$$

where $\xi$ is the damping ratio; $S_{i}$ and $S_{i+1}$ are the $i$ th and $(i+1)$ th area formed by acceleration time history and the time axis.

As shown in Figure 8, the damping of the ribbon bridge is so small that the bridge remains in remarkable motion even after 80 seconds. The identified natural frequencies and damping ratios are very close to those estimated from the SSI method (see Table 2), indicating that both methods are feasible and the identified results are reliable.

\section{Finite Element Modeling}

4.1. Overview of the Finite Element Model. In this section, a sophisticated finite element (FE) model of the stress-ribbon footbridge is established based on the ANSYS platform. The model considers the pretension of the stress ribbon and main nonstructural elements such as deck panels.

The stress-ribbon footbridge consists of three main components, including the precast concrete panels, stress ribbon, and support columns top down. The deck panels 
are modeled as the Shell181 element with uniform thickness and evenly placed on the stress ribbon at a spacing of $0.02 \mathrm{~m}$. The stress ribbon is also considered as the Shell 181 element according to the construction configuration in which the whole curved stress ribbon is divided into several straight plates. The column bracket, consisting of the top plate, bottom plate, and transverse stiffeners, is also modeled by the Shell181 element, as shown in Figure 9(b). The columns are modeled as the Beam188 element with variable cross sections. The three horizontal steel pipes are also modeled as beam elements with uniform cross sections, as shown in Figure 9(c). The three pairs of diagonal cables are modeled by link elements. Only the mass effect of handrails was included in the model since their constraint to the main structure is weak (see Figure 1(d)).

4.2. Material Parameters. The whole bridge mainly consists of two types of steel plates and concrete deck panels. The material parameters of each component were determined through a mechanical test of specimens in the laboratory and are summarized in Table 3.

4.3. Boundary Conditions. The relative linear displacements and rotations between the stress ribbons and the abutments at the contacting area are restrained to zero. The bottom of the columns is treated as fixed boundary conditions (BCs).

According to the construction method, the bridge deck and stress ribbons are well bonded via shear keys, as shown in Figure 1(b). Hence, coupling pairs are set for these points to ensure no relative displacements among them. Similarly, the coupling pairs are set between stress ribbons and the column bracket at the contacting area to ensure they are well coupled.

The boundary conditions (BCs) in the finite element model were firstly determined according to the construction drawings. Then, a trial-and-error method was employed to update the mode based on the principle that the first three natural frequencies as well as mode shapes approach the measured ones. A refined modal test incorporating more vertical modes and lateral modes will be conducted later, and then, a detailed model updating would be implemented to obtain more reasonable BCs.

4.4. Application of Pretension to the Footbridge. The static analysis of the footbridge was firstly conducted only considering its gravity. The stress obtained from the static analysis was further used as the initial pretension forces applied to the stress ribbons before modal analysis. The whole structure has 1291 elements in total. Figures 9(a)-9(c) show the overview and details of the FE model developed here.

4.5. Simulated Modal Properties. Modal analysis was conducted for the pretensioned structure using the block Lanczos method. The first ten modes and natural frequencies were obtained, as shown in Table 4. For comparison, the measured results are also listed in the table. Note that the natural frequencies are presented according to similar mode shapes since some modes are unidentified from the field measurement.

For clarity, Figure 10 further depicts the first ten-mode shapes. Clearly, the stress-ribbon footbridge is characterized by closely spaced modes with the first ten simulated natural frequencies well below $4 \mathrm{~Hz}$. The first ten modes are dominated by vertical bending modes and bending and torsion coupled modes. Since the stress ribbons are asymmetric supported, the main span is more prone to vibrate owing to the larger span length.

The simulated mode shapes showed satisfactory agreement with the measured ones with modal assurance criterion (MAC) value greater than 0.9. The simulated natural frequencies for the first (corresponding to the first measurement, see Table 4) and fifth modes (corresponding to the 3rd measurement) are very close to the measured ones except for the fourth mode (corresponding to the second measurement). This may be attributed to the complex BCs between the stress ribbons and the abutments as well as the contact relationship between the stress ribbons and the column bracket. In fact, the proper modeling of these contacts is challenging since it is hard to quantify the stiffness (rigid or semirigid) and the effective anchorage length in such cases. In general, the FE model developed here can reflect the actual dynamic properties of the test footbridge and thus can be applied in subsequent analysis.

\section{Human-Induced Vibration Test}

5.1. Experimental Setup. This section reports a human-induced vibration test of the stress-ribbon footbridge to further evaluate the dynamic performance under normal operating conditions. Test cases consisted of a controlled synchronized walking test of both single-person and multiple-person cases as well as random walking. Besides, an unexpected case such as group running was also considered. A total of seven participants was recruited for the test. The basic information, including gender, age, height, and body mass, is given in Table 5. Table 6 summarizes the detailed test cases. In the single-person walking test, four individuals were considered in the test to account for the intersubject variability [8]. For the multiple-person case, seven TSs formed in a line $(7 \times 1)$ as a small group were considered. Walking frequencies at $1.44 \mathrm{~Hz}$ and $1.67 \mathrm{~Hz}$ were selected to excite the structural resonant response. During the controlled test, test subjects (TSs) were instructed by a metronome to realize the target frequency.

5.2. Results. All measured data were firstly filtered using a Butterworth band-pass filter. The cut-off frequency is 0.1 to $10 \mathrm{~Hz}$. Components below $0.1 \mathrm{~Hz}$ are mainly trend items and components above $10 \mathrm{~Hz}$ are not pronounced since the main structural frequencies and excitation frequencies all fall within $10 \mathrm{~Hz}$. The measured data were analyzed in both time and frequency domains. 


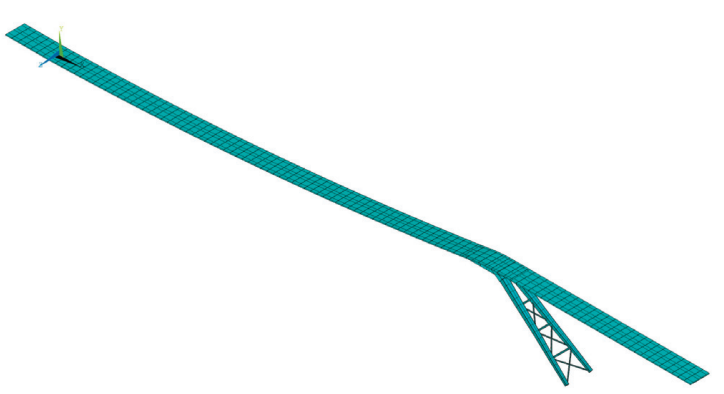

(a)

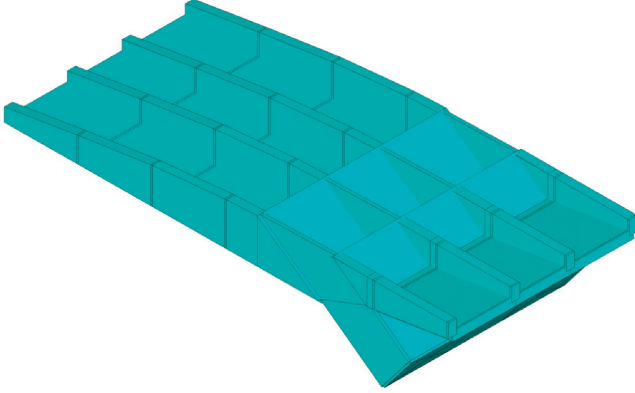

(b)

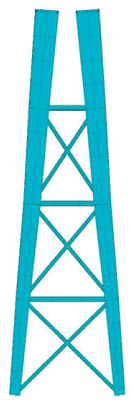

(c)

Figure 9: FE model of the bridge. (a) Overall FE model; (b) configuration of column bracket (without a top plate for clarity); (c) configuration of columns.

TABle 3: Material parameters.

\begin{tabular}{lcccc}
\hline Component type & Material & Density $\left(\mathrm{kg} / \mathrm{m}^{3}\right)$ & Elastic modulus $(\mathrm{MPa})$ & Poisson's ratio \\
\hline Stress ribbon & Q690 steel & 7698 & $2.06 \times 10^{5}$ & 0.3 \\
Column & Q420 steel & 7850 & $2.06 \times 10^{5}$ & 0.3 \\
Bridge deck & C30 concrete & 2500 & $3.00 \times 10^{4}$ & 0.2 \\
\hline
\end{tabular}

TABle 4: Dynamic characteristics of the bridge.

\begin{tabular}{|c|c|c|c|}
\hline \multirow{2}{*}{ Modal no. } & \multicolumn{2}{|c|}{ Frequency $(\mathrm{Hz})$} & \multirow{2}{*}{ Modal description } \\
\hline & Simulated & Measured & \\
\hline 1 & 0.95 & 0.95 & $1^{\text {st }}$ vertical bending (main span) \\
\hline 2 & 0.97 & - & $1^{\text {st }}$ lateral bending + torsion (main span) \\
\hline 3 & 1.09 & - & $2^{\text {nd }}$ vertical bending (main span) \\
\hline 4 & 1.65 & 1.45 & $3^{\text {rd }}$ vertical bending (main span $)+1^{\text {st }}$ vertical bending (side span) + lateral (column) \\
\hline 5 & 1.71 & 1.68 & $3^{\text {rd }}$ vertical bending (main span) $+1^{\text {st }}$ vertical bending (side span) \\
\hline 6 & 2.20 & - & $1^{\text {st }}$ torsion (main span) \\
\hline 7 & 2.27 & - & $4^{\text {th }}$ vertical bending (main span) \\
\hline 8 & 2.89 & - & $5^{\text {th }}$ vertical bending (main span) \\
\hline 9 & 3.15 & - & $2^{\text {nd }}$ lateral bending + torsion (main span) \\
\hline 10 & 3.47 & - & $6^{\text {th }}$ vertical bending (main span) \\
\hline
\end{tabular}

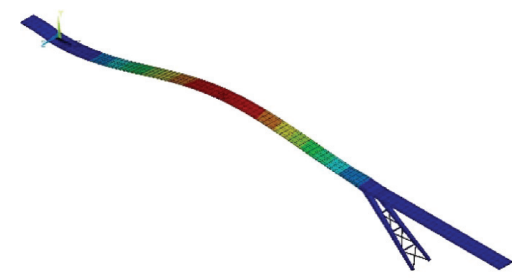

(a)

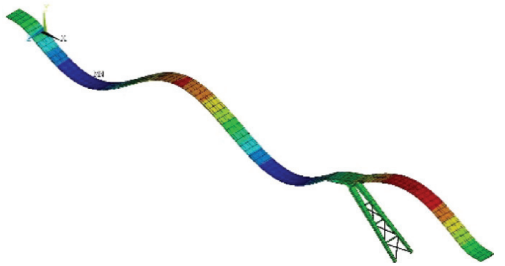

(d)

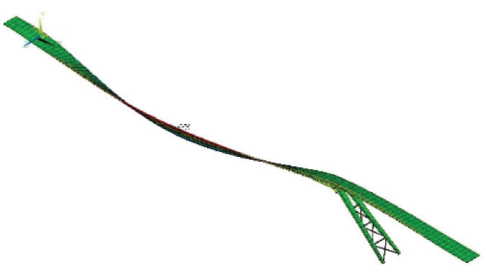

(b)

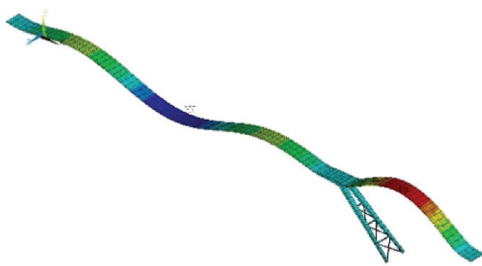

(e)

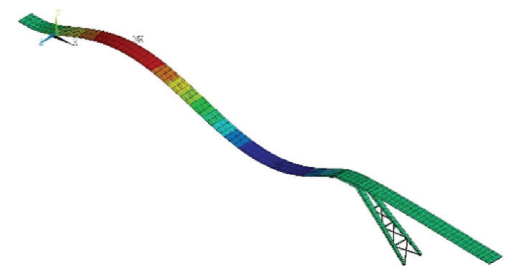

(c)

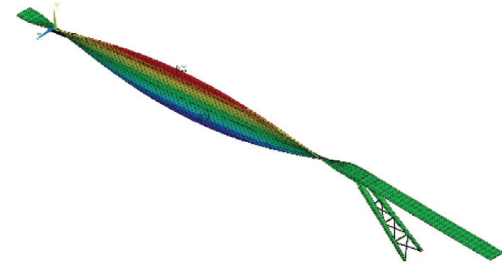

(f)

Figure 10: Continued. 


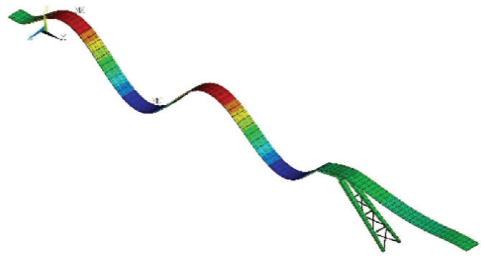

(g)

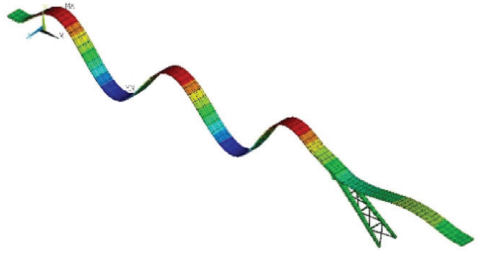

(h)

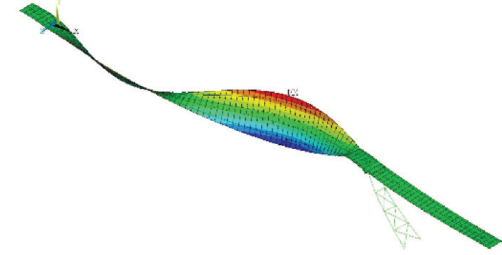

(i)

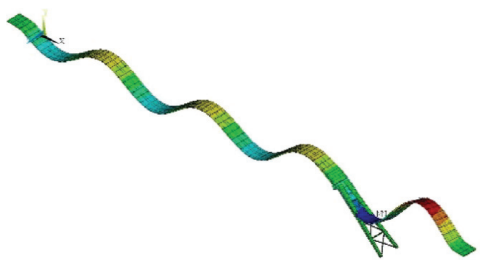

(j)

FIGURE 10: First ten simulated modes of the footbridge. (a) 1st vertical bending (main span), $0.95 \mathrm{~Hz}$. (b) 1st lateral bending + torsion (main span), $0.97 \mathrm{~Hz}$. (c) 2nd vertical bending (main span), $1.09 \mathrm{~Hz}$. (d) 3rd vertical bending (main span) + 1st vertical bending (side span) + lateral (column), 1.65 Hz. (e) 3rd vertical bending (main span) + 1st vertical bending (side span), 1.71 Hz. (f) 1st torsion (main span), $2.20 \mathrm{~Hz}$. (g) 4 th vertical bending (main span), $2.27 \mathrm{~Hz}$. (h) 5 th vertical bending (main span), $2.89 \mathrm{~Hz}$. (i) 2nd lateral bending + torsion (main span), $3.15 \mathrm{~Hz}$. (j) 6th vertical bending (main span), $3.47 \mathrm{~Hz}$.

TABLE 5: Basic information of the test subject.

\begin{tabular}{lcccc}
\hline Test subject no. & Gender & Age (years) & Height $(\mathrm{m})$ & Body mass $(\mathrm{kg})$ \\
\hline S1 & M & 25 & 170 & 183 \\
S2 & M & 23 & 174 & 70.0 \\
S3 & M & 37 & 177 & 80.0 \\
S4 & M & 24 & 171 & 100.0 \\
S5 & M & 34 & 167 & 67.0 \\
S6 & F & 23 & 167 & 58.5 \\
S7 & F & 22 & {$[172.7,5.8]$} & 56.0 \\
[Mean, std] & - & {$[26.9,6.0]$} & {$[69.5,16.1]$} \\
\hline
\end{tabular}

Note. M: male; F: female; std: standard deviation.

TABLE 6: Summary of all test cases.

\begin{tabular}{lc}
\hline Case no. & Case description \\
\hline 1 & $\mathrm{~S} 1$ walking at $1.67 \mathrm{~Hz}$ \\
2 & $\mathrm{~S} 2$ walking at $1.67 \mathrm{~Hz}$ \\
3 & $\mathrm{~S} 3$ walking at $1.67 \mathrm{~Hz}$ \\
4 & $\mathrm{~S} 4$ walking at $1.67 \mathrm{~Hz}$ \\
5 & Group $(7 \times 1, \mathrm{~S} 1 \sim \mathrm{S} 7)$ walking at $1.44 \mathrm{~Hz}$ \\
6 & Group $(7 \times 1, \mathrm{~S} 1 \sim \mathrm{S} 7)$ walking at $1.67 \mathrm{~Hz}$ \\
7 & Group $(7 \times 1, \mathrm{~S} 1 \sim \mathrm{S} 7)$ running at 3.0 Hz \\
8 & Random walking $(7 \times 1, \mathrm{~S} 1 \sim \mathrm{S} 7)$ \\
\hline
\end{tabular}

In time-domain analysis, both the peak value and rootmean-square (RMS) acceleration were considered. Compared with the peak value, the RMS value, which considers the average energy during the vibration period (defined as equation (2)), gives more stable estimates.

$$
a_{\mathrm{RMS}}=\sqrt{\int_{0}^{T} a(t)^{2} \mathrm{~d} t},
$$

where $a(t)$ is the time history, and $T$ is the time duration of the vibration event. It should be noted that $a_{\mathrm{RMS}}$ largely depends on the selection of $T$. The time duration of $1 \mathrm{~s}$ is adopted here according to ISO 10137(2007) [32].

Table 7 summarizes the peak and $1 \mathrm{~s}$-RMS values of the bridge acceleration under walking pedestrians. Clearly, the maximum bridge acceleration is $2.14 \mathrm{~m} / \mathrm{s}^{2}$ for the group $(7 \times 1)$ walking at $1.67 \mathrm{~Hz}$; however, for random group walking, the peak acceleration reduces to $0.43 \mathrm{~m} / \mathrm{s}^{2}$.

Figures 11(a)-11(f) show an example of bridge acceleration and its spectrum at the center of the side span (TP12) under different walking cases. The 1s-RMS acceleration is also plotted in the time-domain figures. As 
TABle 7: Peak acceleration and maximum $1 \mathrm{~s}-\mathrm{RMS}\left(\mathrm{m} / \mathrm{s}^{2}\right)$.

\begin{tabular}{|c|c|c|c|c|c|c|c|c|}
\hline \multirow{2}{*}{ Case no. } & \multicolumn{4}{|c|}{ Peak acceleration } & \multicolumn{4}{|c|}{ RMS $(T=1 \mathrm{~s})$} \\
\hline & Main span $1 / 2$ & Main span $1 / 4$ & Side span $1 / 4$ & Side span $1 / 2$ & Main span $1 / 2$ & Main span $1 / 4$ & Side span $1 / 4$ & Side span $1 / 2$ \\
\hline 1 & 0.07 & 0.13 & 0.22 & 0.31 & 0.04 & 0.07 & 0.12 & 0.20 \\
\hline 2 & 0.07 & 0.19 & 0.37 & 0.53 & 0.03 & 0.12 & 0.21 & 0.34 \\
\hline 3 & 0.09 & 0.20 & 0.39 & 0.62 & 0.05 & 0.14 & 0.25 & 0.40 \\
\hline 4 & 0.21 & 0.33 & 0.46 & 0.67 & 0.11 & 0.17 & 0.28 & 0.46 \\
\hline 5 & 0.63 & 0.95 & 0.44 & 0.48 & 0.38 & 0.58 & 0.23 & 0.35 \\
\hline 6 & 0.60 & 0.86 & 1.17 & 2.14 & 0.35 & 0.49 & 0.86 & 1.40 \\
\hline 7 & 0.67 & 1.20 & 2.12 & 0.72 & 0.39 & 0.70 & 1.38 & 0.28 \\
\hline 8 & 0.36 & 0.43 & 0.28 & 0.33 & 0.18 & 0.21 & 0.12 & 0.14 \\
\hline
\end{tabular}

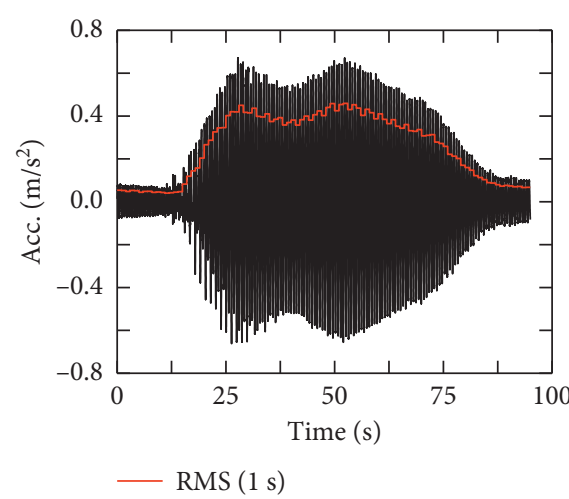

(a)

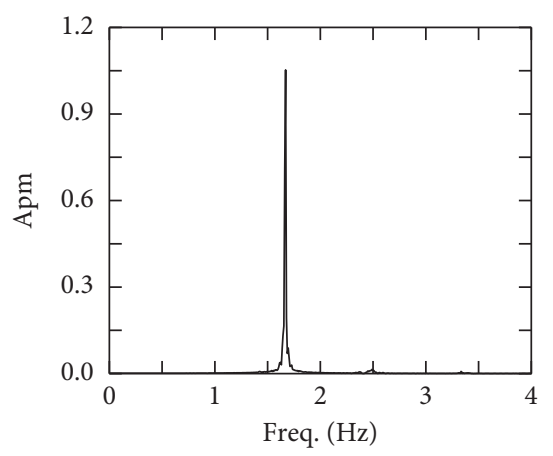

(d)

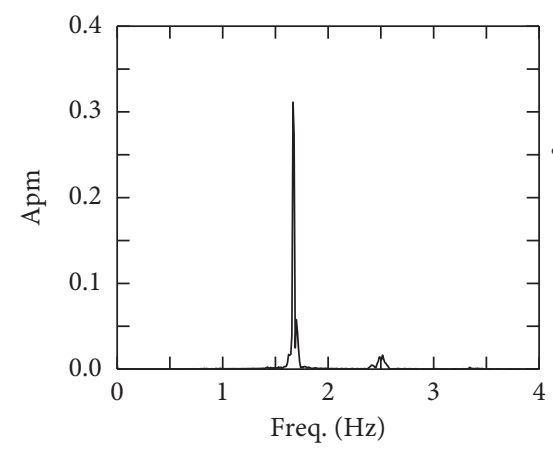

(b)

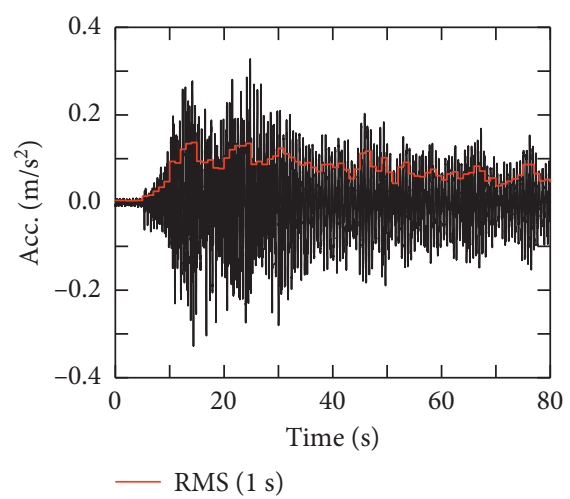

(e)

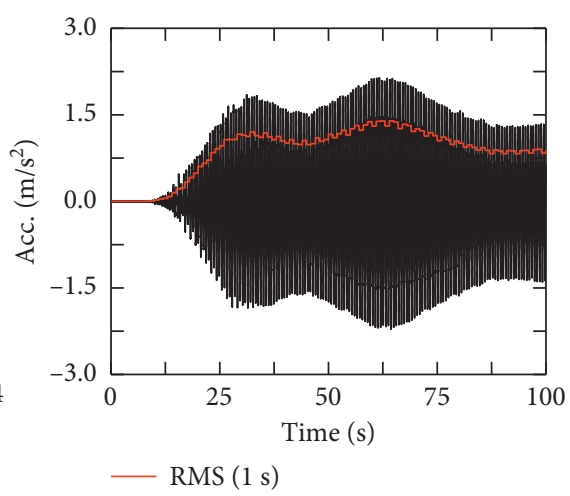

(c)

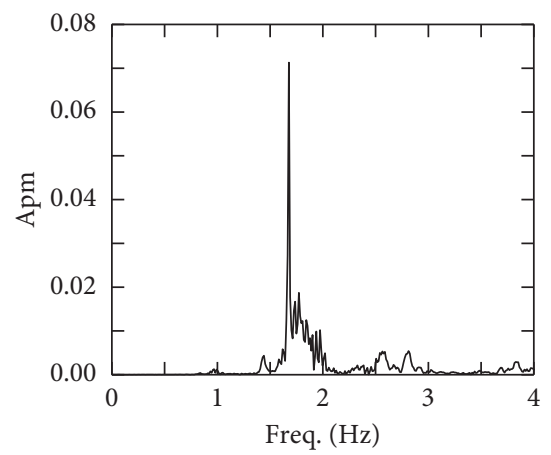

(f)

FIgURE 11: Measured bridge acceleration at TP12 (center of side span) in both time and frequency domains. (a) S4 walking at $1.67 \mathrm{~Hz}$, time domain. (b) S4 walking at $1.67 \mathrm{~Hz}$, frequency domain. (c) Group $(7 \times 1)$ walking at $1.67 \mathrm{~Hz}$, time domain. (d) Group $(7 \times 1)$ walking at $1.67 \mathrm{~Hz}$, frequency domain. (e) Random walking $(7 \times 1)$, time domain. (f) Random walking $(7 \times 1)$, frequency domain.

expected, the resonant response was observed when walking frequency approaches bridge natural frequency. The bridge response consists of both excitation frequencies and the first few structural frequencies, as shown in Figures 11(b), 11(d), and 11(f). The bridge acceleration at TP 12 is $0.67 \mathrm{~m} / \mathrm{s}^{2}$ for single-person S4 walking at $1.67 \mathrm{~Hz}$ (corresponding to the first vertical bending mode of side span). It reaches $2.14 \mathrm{~m} / \mathrm{s}^{2}$ for the group $(7 \times 1)$ synchronized walking at $1.67 \mathrm{~Hz}$; however, it reduces to $0.33 \mathrm{~m} / \mathrm{s}^{2}$ under random group walking.

A comparison of bridge acceleration between singleperson and multiperson walking cases indicates that pedestrian numbers do not linearly amplify the bridge response under multiple-person. A comparison of bridge acceleration between single-person, group synchronized walking, and random walking cases implies that the bridge response is most sensitive to step frequency. This is also in accordance with a previous study by He and Xie [8]. Moreover, the acceleration spectrum curve under random walking is much wider than synchronized walking, showing the narrow-band and stochastic features of random walking [1].

Figures 12(a)-12(d) further compare the bridge acceleration spectrum at the center of the side span (TP12) for all test cases. It is evident that the human-induced bridge responses show obvious forced vibration features. The bridge response consists of both excitation frequencies and structural frequencies. 


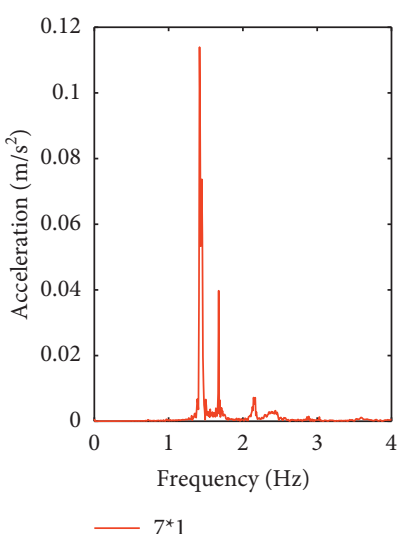

(a)
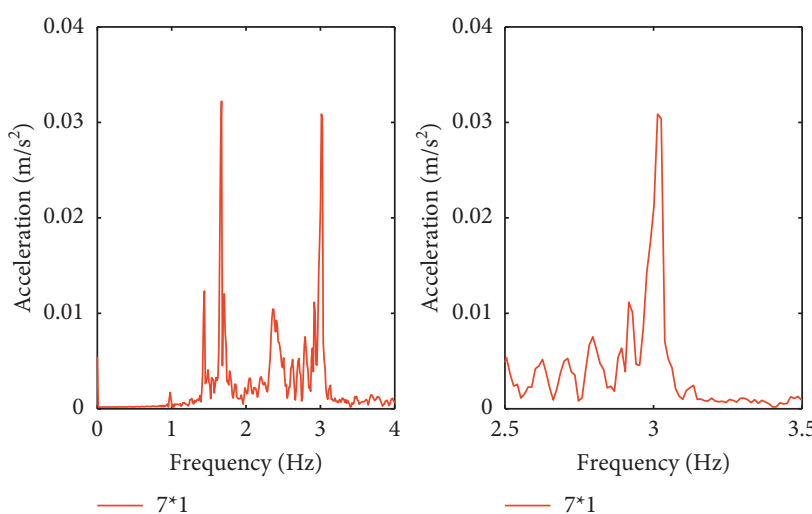

(c)

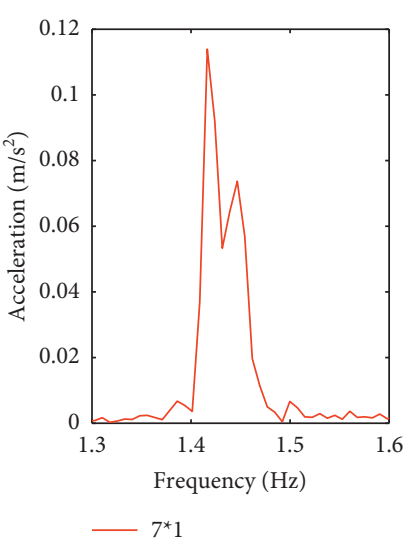

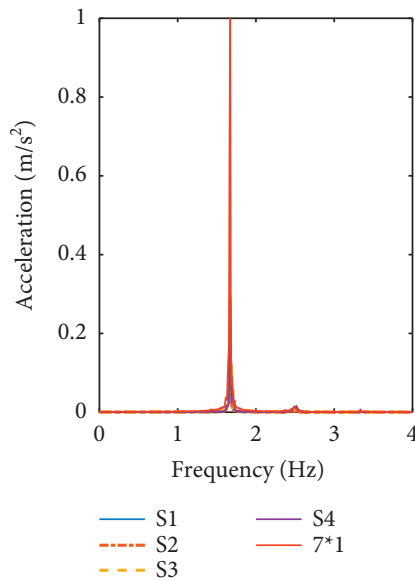

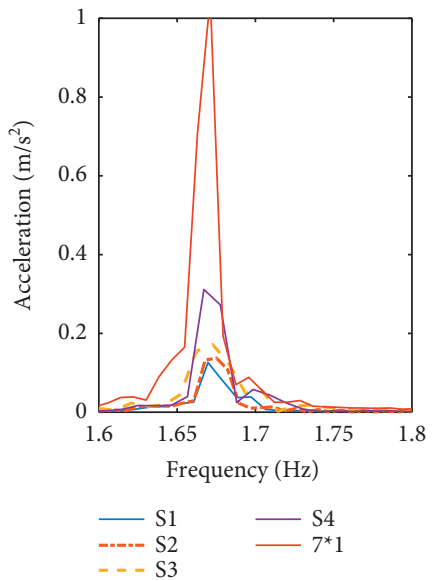

(b)
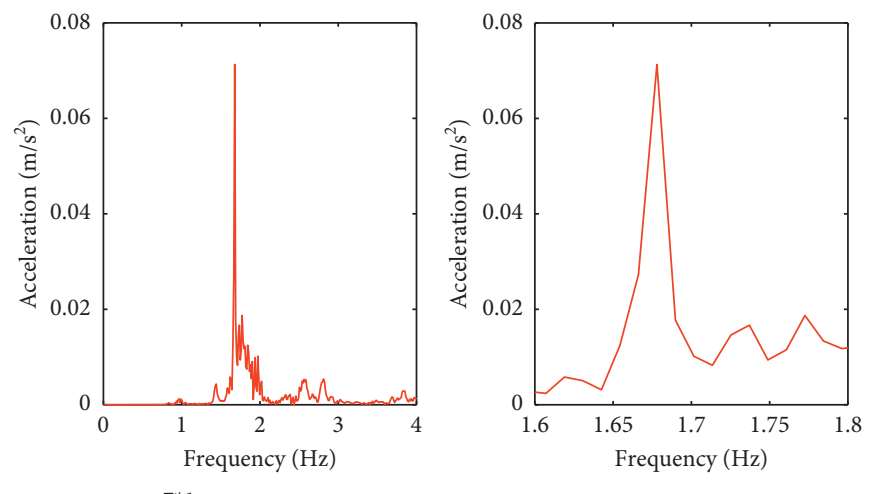

(d)

FIGURE 12: Frequency spectrum: (a) Group $(7 \times 1)$ walking at $1.44 \mathrm{~Hz}$; (b) single-person and multiperson $(7 \times 1)$ walking at $1.67 \mathrm{~Hz}$; (c) group $(7 \times 1)$ running at $3.0 \mathrm{~Hz}$; $(\mathrm{d})$ group $(7 \times 1)$ random walking.

As shown in Figure 12(b), the bridge acceleration spectrum under different single-person walking cases is similar but varies in magnitude. The normalized spectrum (acceleration spectrum divided by body weight) for each individual also varies, implying the intersubject variability $[1,2]$. The spectrum gets wider for group walking at $1.67 \mathrm{~Hz}$ compared with single-person cases, which may attribute to the increase of system damping owing to more pronounced humanstructure interaction at a larger mass participant ratio. This is in accordance with experimental finds in [8]. Compared with single-person walking, the bridge response under multipleperson is not linearly amplified by pedestrian number.

Figure 12(c) also exhibits a typical forced vibration feature. Both structural frequencies and excitation frequencies were observed. There is some leakage for frequencies between 2.5 and $3.0 \mathrm{~Hz}$. This may be attributed to the imperfect synchronization among group people when running along a sloped deck at $3.0 \mathrm{~Hz}$.

Figures 13(a) and 13(b) give the correlation between bridge peak acceleration, 1s-RMS, and step frequency. The bridge reaches maximum acceleration for step frequencies at $1.67 \mathrm{~Hz}$ and $3.0 \mathrm{~Hz}$. This is reasonable since $1.67 \mathrm{~Hz}$ corresponds to the first vertical bending mode of the side span (see Table 4). The $3.0 \mathrm{~Hz}$ may also be close to the vertical bending frequency of the side span (a clear peak was observed at $3.0 \mathrm{~Hz}$, as shown in Figure 6(a)). A comparison of bridge acceleration between single-person and group random walking cases implies that the bridge response is more sensitive to step frequency rather than the number of pedestrians.

\section{Analytical Verification}

6.1. Mathematical Formulation. Consider a simply supported Euler beam with span length $L$ and constant crosssection $A$ subjected to a walking pedestrian. The beam has bending stiffness EI, mass per unit length $m_{b}$, and damping ratio $c$. The walking pedestrian is considered an SDOF system with biomechanical excited force [33]. Figure 14 gives the schematic illustration of the bridge-walking pedestrian coupled system.

The motion equation of the beam under a walking excitation is given by

$$
\text { EI } \frac{\partial^{4} w}{\partial x^{4}}+m_{b} \frac{\partial^{2} w}{\partial t^{2}}+\frac{\partial w}{\partial t}=F_{p}(x, t),
$$

where $w$ is the beam deflection and $F_{p}(x, t)$ is the contact force between the bridge and walking people: 


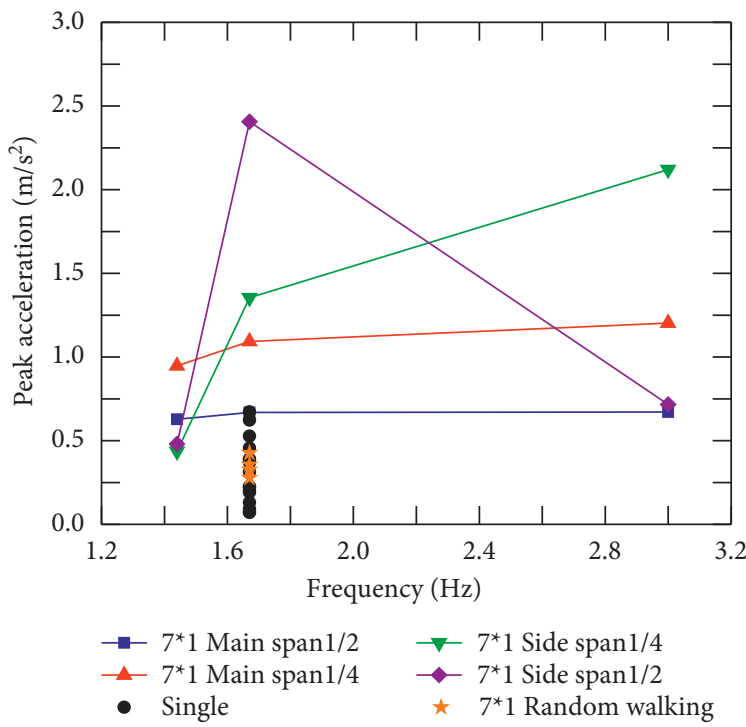

(a)

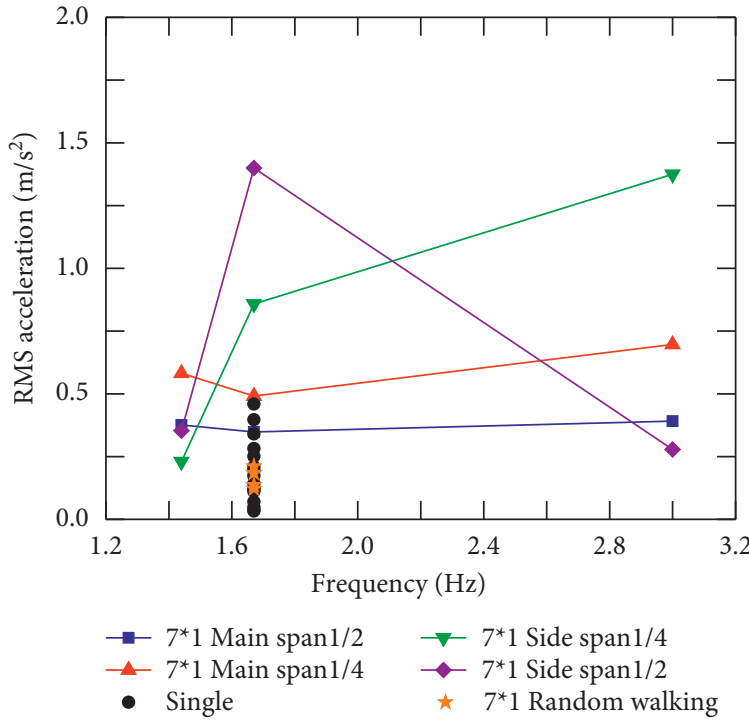

(b)

FIgURE 13: Correlation between bridge (a) peak acceleration, (b) 1 s RMS, and step frequency.

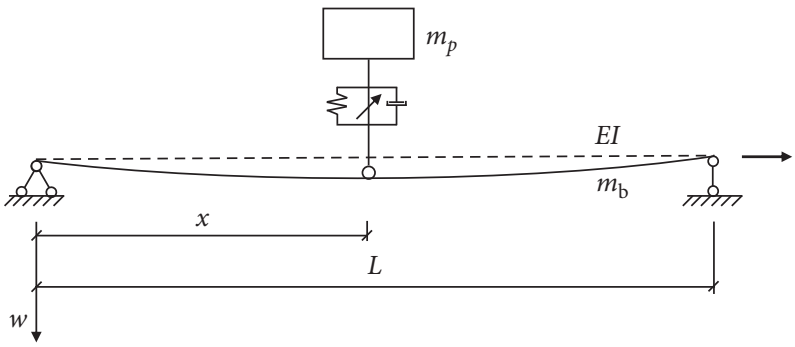

FIGURE 14: Schematic view of the human-structure interaction model.

$$
F_{p}(x, t)=f_{p}(t) \cdot \delta(x-x p(t))
$$

in which $\delta(\cdot)$ is the Dirac delta function, and $f_{p}(t)$ is the human-structure interaction force, which could be represented using the body motion as follows:

$$
f_{p}(t)=-m_{p} g-m_{p} a_{c}(t)
$$

where $m_{p}$ is the human body mass and $a_{c}(t)$ is the acceleration at the center of mass (CoM).

The CoM acceleration $a_{c}(t)$ consists of two parts, namely, the relative acceleration with respect to the bridge $a_{c r}(t)$ and the associated acceleration with respect to the bridge $a_{c e}(t)$; that is,

$$
a_{c}(t)=a_{c r}(t)+a_{c e}(t) .
$$

The associated bridge acceleration where the human located, $a_{c e}(t)$, is given by

$$
a_{c e}(t)=\frac{\partial^{2} w\left(x_{p}, t\right)}{\partial t^{2}} .
$$

Assume that the bridge vibration has little impact on the human walking pattern; we have

$$
a_{c r}(t)=\frac{\hat{f}_{p}(t)-m_{p} g}{m_{p}},
$$

where $\hat{f}_{p}(t)$ is the ground reaction force (GRF) on the rigid floor.

Substituting equations (4) (8) into equation (3) yields

$$
\begin{aligned}
& \mathrm{EI} \frac{\partial^{4} w}{\partial x^{4}}+m_{b} \frac{\partial^{2} w}{\partial t^{2}}+c \frac{\partial w}{\partial t} \\
& =-\left(\hat{f}_{p}(t)-m_{p} \frac{\partial^{2} w\left(x_{p}, t\right)}{\partial t^{2}}\right) \delta\left(x-x_{p}(t)\right) .
\end{aligned}
$$

Note that equation (9) treats the human-structure interaction force as a summation of GRF on the rigid floor, $\widehat{f}_{p}(t)$, and the inertial force of the human body owing to bridge oscillation.

Based on the mode superposition method, the beam displacement is rewritten as

$$
w(x, t)=\sum_{i=1}^{\infty} q_{i}(t) \phi_{i}(x),
$$

in which $\phi_{i}(x)$ and $q_{i}(t)$ are the ith mode shape and corresponding generalized coordinate, respectively. In practice, using only a few modes can give satisfactory predictions since the contribution of higher modes to the total structural response is not pronounced. 
For a simply supported beam, the mode shape $\phi_{j}(x)$ is

$$
\phi_{j}(x)=\sin \frac{j \pi x}{L} .
$$

Substituting equation (10) into equation (9) yields

$$
\begin{aligned}
& \mathrm{EI} \sum_{i=1}^{\infty} \dot{q}_{i}(t) \phi_{i}{ }^{(4)}(x)+m_{b} \sum_{i=1}^{\infty} \phi(x) \ddot{q}_{i}(t)+c \sum_{i=1}^{\infty} \phi_{i}(x) \dot{q}_{i}(t) \\
& =-\delta\left(x-x_{p}(t)\right)\left[\widehat{f}_{p}(t)+m_{p} \sum_{i=1}^{\infty} \phi\left(x_{p}\right) \ddot{q}_{i}(t)\right] .
\end{aligned}
$$

Multiplying $\varphi_{j}(x)$ on both sides of equation (12) and integrating along the beam length within $[0, L]$ leads to

$$
\begin{aligned}
\dot{q}_{j}(t) & +\frac{2}{m_{b} L} m_{p} \phi_{j}\left(x_{p}\right) \sum_{i=1}^{\infty} \phi\left(x_{p}\right) \ddot{q}_{i}(t) \\
& +2 \zeta_{n} w_{n} \dot{q}_{j}(t)+w_{n}^{2} q_{j}(t) \\
= & \frac{-2}{m_{b} L} \widehat{f}_{p}\left(\phi_{j}\right)\left(x_{p}(t)\right) .
\end{aligned}
$$

If $N$ modes are considered for the bridge, the bridgemoving pedestrian coupled system could be rewritten in a discrete matrix form as

$$
\mathbf{M U}+\mathbf{C} \ddot{U}+\mathbf{K U}=\mathbf{F},
$$

where $\mathbf{M}, \mathbf{C}$, and $\mathbf{K}$ are the $N \times N$ mass, damping, and stiffness matrix, respectively; $\mathbf{U}, \dot{\mathbf{U}}$, and $\ddot{\mathbf{U}}$ are the $N$-vectors for independent displacement, velocity, and acceleration, respectively. That is,

$$
\begin{aligned}
& \mathbf{M}=\left[\begin{array}{cccc}
1+p_{M} \phi_{11} & p_{M} \phi_{12} & \ldots & p_{M} \phi_{1 N} \\
p_{M} \phi_{21} & 1+p_{M} \phi_{21} & \ldots & p_{M} \phi_{2 N} \\
\ldots & \ldots & \ldots & \ldots \\
p_{M} \phi_{N 1} & p_{M} \phi_{N 1} & \ldots & 1+p_{M} \phi_{N N}
\end{array}\right], \\
& \mathbf{C}=\left[\begin{array}{llll}
2 \zeta_{1} w_{1} & & & \\
& 2 \zeta_{2} w_{2} & & \\
& & \ddots & \\
& & & 2 \zeta_{n} w_{n}
\end{array}\right] \\
& \mathbf{K}=\left[\begin{array}{llll}
w_{1}^{2} & & & \\
& w_{2}^{2} & & \\
& & \ddots & \\
& & & w_{n}^{2}
\end{array}\right] \text {, } \\
& \mathbf{U}=\left\{\mathbf{q}_{1}, \mathbf{q}_{2}, \ldots \mathbf{q}_{N}\right\}^{T},
\end{aligned}
$$

$$
\begin{aligned}
\mathbf{F} & =\left[p_{F} \phi_{1}, p_{F} \phi_{2}, \ldots p_{F} \phi_{N},\right]^{T} . \\
\rho_{m} & =\frac{2 m_{p}}{m_{b} L} \\
\rho_{F} & =-\frac{2}{m_{b} L} \widehat{f}_{p}, \\
\phi_{n} & =\sin \frac{n \pi x_{p}}{L}, \\
\Phi_{n m} & =\phi_{n} \phi_{m} .
\end{aligned}
$$

Note that equation (14) is a time-varying system since the mass, damping, and stiffness matrix all change with the human location. One GRF $\hat{f}_{p}$ is given, equation (14) could be solved (e.g., using the Newmark- $\beta$ method).

6.2. GRF of a Walking Pedestrian. Previous studies showed that the GRF under human walking has a strong periodical character owing to the unique walking pattern of human beings [1]. The GRF could mathematically be represented as the summation of several Fourier series, expressed as [1]

$$
F_{v}(t)=G\left(1+\sum_{i=1}^{n} \alpha_{i} \sin \left(2 \pi i f_{n} t+\varphi_{i}\right)\right)
$$

where $F_{v}(t)$ is the vertical footfall force, $G$ is the bodyweight, $n$ is the number of harmonics to be considered, $\alpha_{i}$ is the ith dynamic load factor (DLF), $f_{n}$ is the fundamental step frequency, and $\varphi_{i}$ is the $i$ th phase angle.

The formula is simple and has a clear physical meaning, but the parameters such as DLFs and phase angles may vary from person to person [1]. To this end, TSs involved in the walking test on the stress-ribbon bridge were tested on a rigid floor to obtain their GRF directly. The wireless pressure insoles (see Figure 15(a)) produced by Loadsol were employed for footfall force measurement. The smartphone (iPhone 7 plus, see Figure 15(b)), which has built-in accelerometers and gyroscopes, was used to record the body acceleration during walking. Previous studies [34, 35] showed that the C7, sternum, and lower back are satisfactory candidates to present body motion. In this study, the smartphone was well fastened on the lower back (see Figure 15(d)) to capture body motion since it is easy to fasten and has little effect on human movement.

Before the measurement, the insoles were calibrated via standing with a single foot since the supporting foot is expected to have total static weight. The resolution of the smartphone in acceleration capture was also checked by comparing it with a high-resolution wireless inertial measurement unit (IMU) produced by Xsense. Figure 16 shows an example of the comparison between the smartphone and IMU in both time and frequency domains. Results show that the smartphone has satisfactory resolution and can be used in the subsequent measurement. 

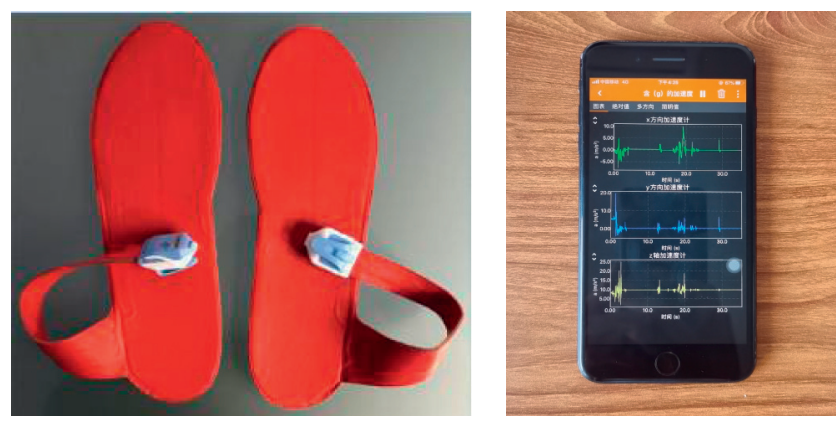

(a)

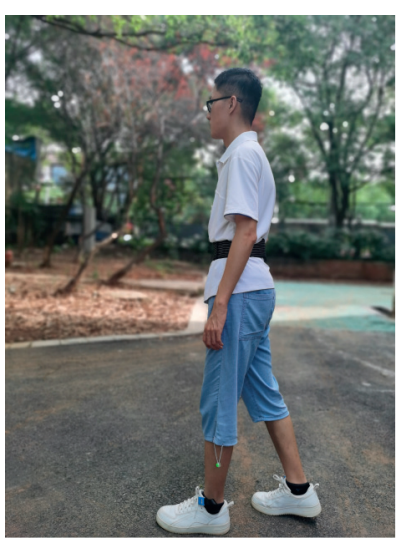

(c)

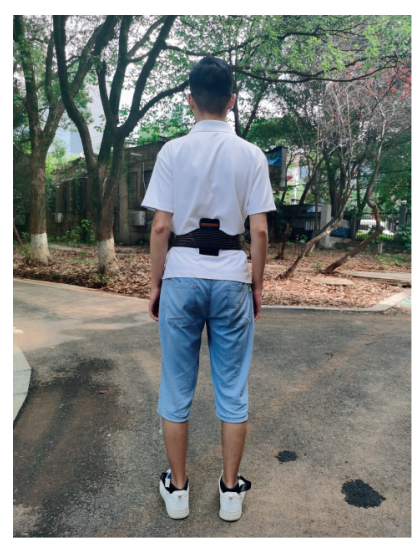

(d)

Figure 15: Test instruments and test scenario: (a) wireless pressure insoles; (b) smartphone; (c) and (d) installation of test instruments.
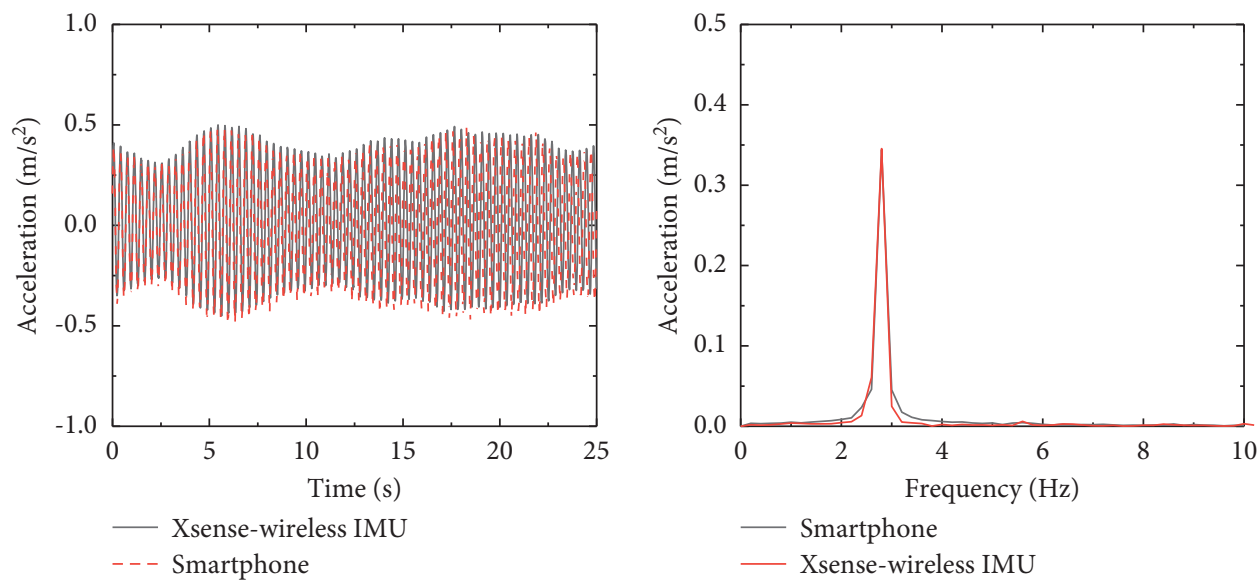

(a)

FIgURE 16: Comparison of human body acceleration (lower back) obtained from wireless IMU and smartphone (iPhone 7 plus). (a) Time domain and (b) frequency domain.

Figure 17 gives the continuous vertical GRF for singleperson walking at $1.6 \mathrm{~Hz}, 1.8 \mathrm{~Hz}, 2.0 \mathrm{~Hz}, 2.2 \mathrm{~Hz}$, and $2.4 \mathrm{~Hz}$ in both time and frequency domains. It is evident that the GRF shows prominent periodical features for all step frequencies. The GRF consists of several primary harmonics and subharmonics. The DLF generally attenuates as the order increases. The contribution of primary harmonics is generally more significant than subharmonics. However, for some cases (i.e., $2.2 \mathrm{~Hz}$ ), the subharmonic is so pronounced and cannot be ignored. This is in accordance with a previous study by Zivanovic et al. [1].

Figure 18 illustrates the corresponding body acceleration in the vertical direction for single-person walking at various step frequencies. Clearly, the body motion also shows typical periodical characteristics. The spectrum of body acceleration is similar to that of GRF, demonstrating that the inertial of body motion is the leading cause of footfall force oscillation.

Since all measured footfall forces have similar features, GRF that consists of both primary harmonics and subharmonics was used for the subsequent numerical modeling.
6.3. Comparison of the Theoretical Results with Experimental Data. Based on the FE model developed in Section 4 and the measured GRF of all involved individuals in the walking test, the methodology developed in Section 6.1 was applied to the stress-ribbon footbridge to check its validity.

Equations (14) and (15a)-(15f) show that the coupled system is time-varying since the mass, damping, and stiffness matrix changes with the human location. In this study, an iteration procedure is developed to solve the problem based on the combination of MATLAB and ANSYS platforms. The basic procedure of the iteration process is shown in Figure 19.

Figures 20 and 21 compare the simulated and measured bridge acceleration time history and Fourier spectrum at the center of the main span and side span, respectively, under a single-person walking at $1.67 \mathrm{~Hz}$. The simulated time history and spectrum distribution are very close to the measured ones. The magnitude of the simulated acceleration is slightly greater than the measured one for both the center of the main span and side span. This may be attributed to the fact that GRF measured on the rigid floor is 

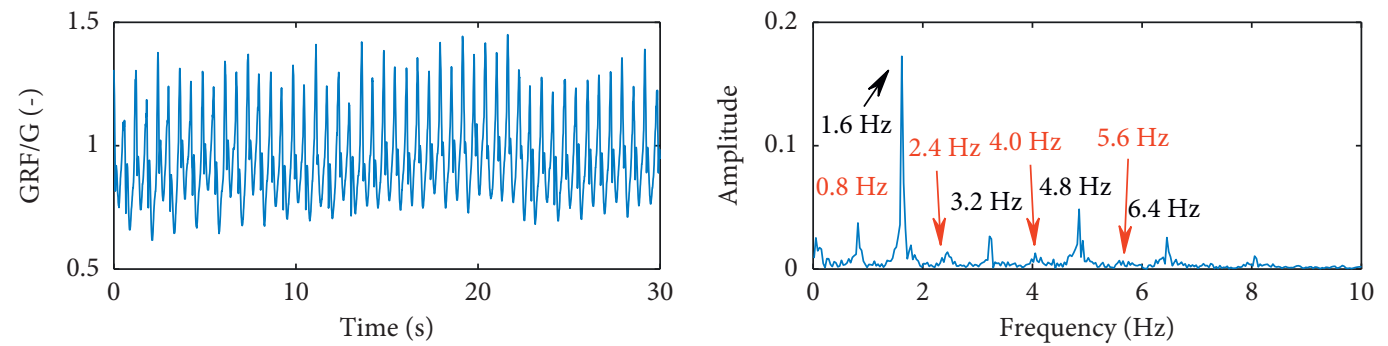

(a)
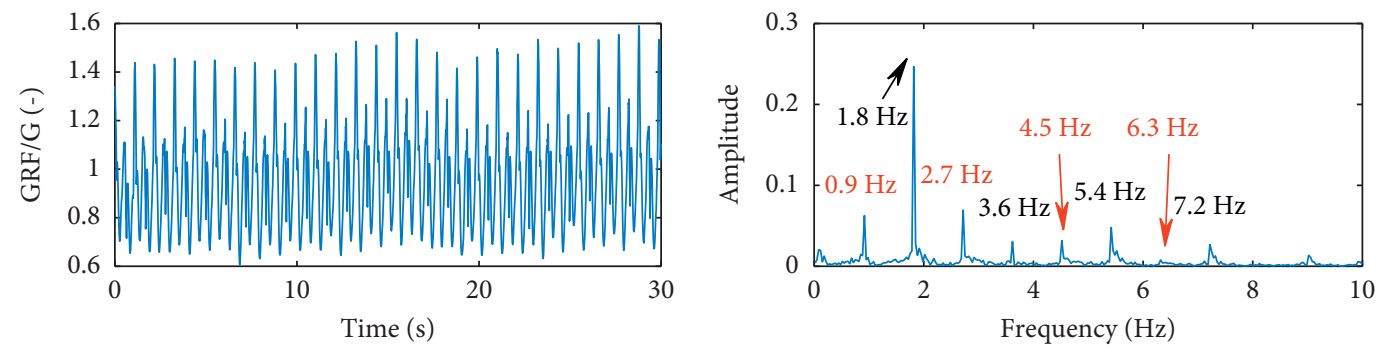

(b)
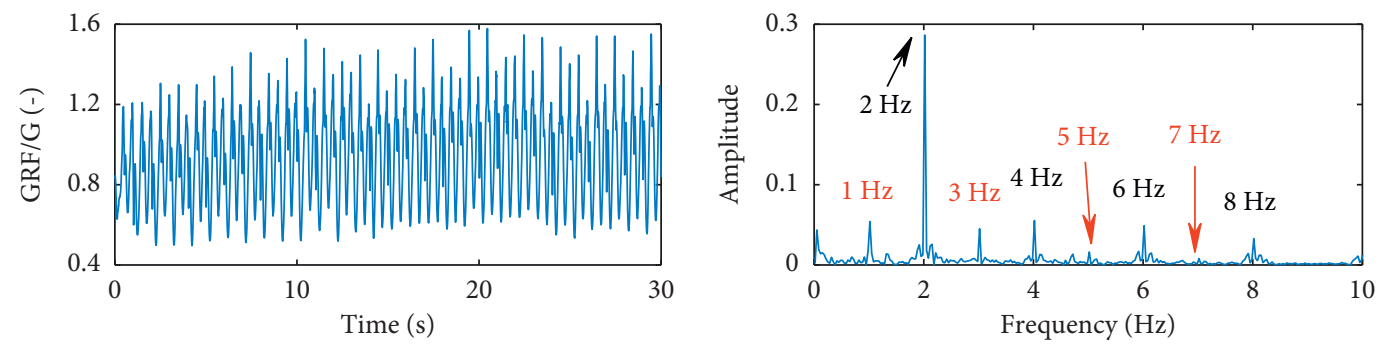

(c)
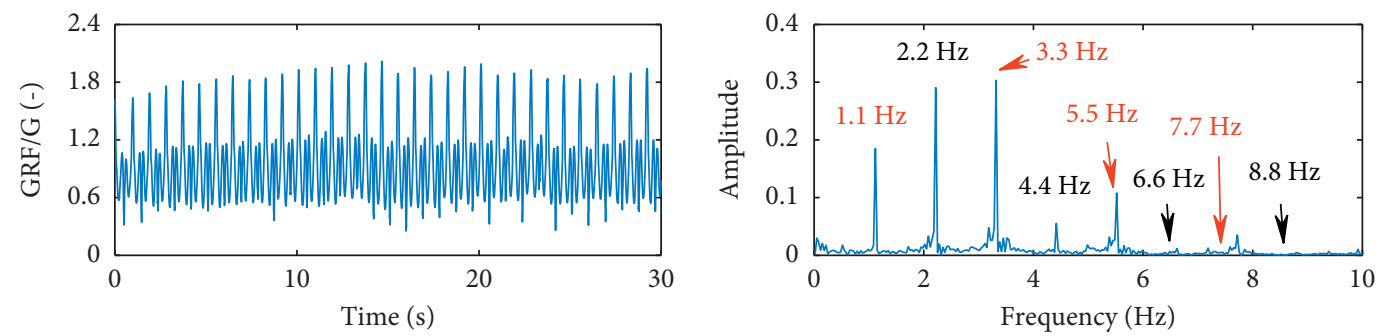

(d)
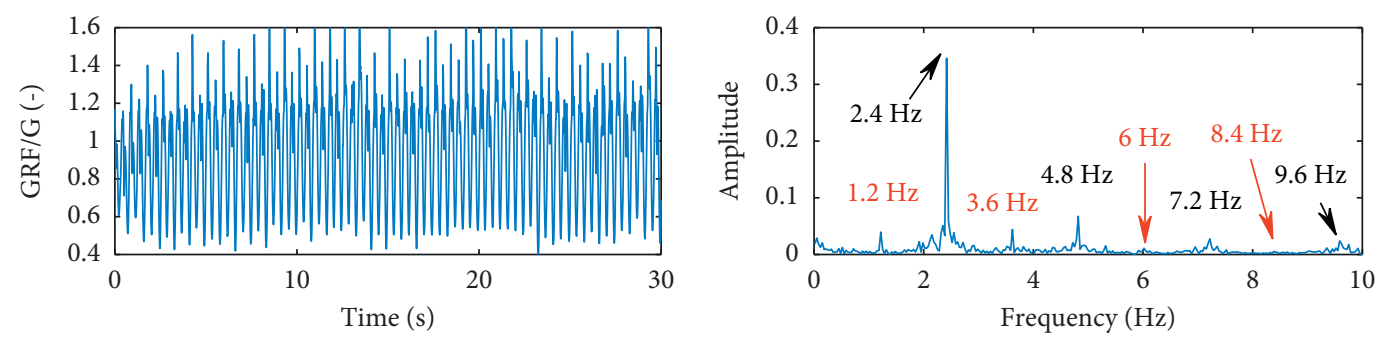

(e)

FIGURE 17: Vertical GRF for a single-person walking at step frequencies of (a) $1.6 \mathrm{~Hz}$, (b) $1.8 \mathrm{~Hz}$, (c) $2.0 \mathrm{~Hz}$, (d) $2.2 \mathrm{~Hz}$, and (e) $2.4 \mathrm{~Hz}$ in time and frequency domains.

used in the present study. In fact, the footfall force would be smaller on a flexible footbridge than on a rigid floor owing to human-structure interaction. The simulated results generally show satisfactory agreement with the measured ones, demonstrating that the proposed analytical model is valid and effective. 

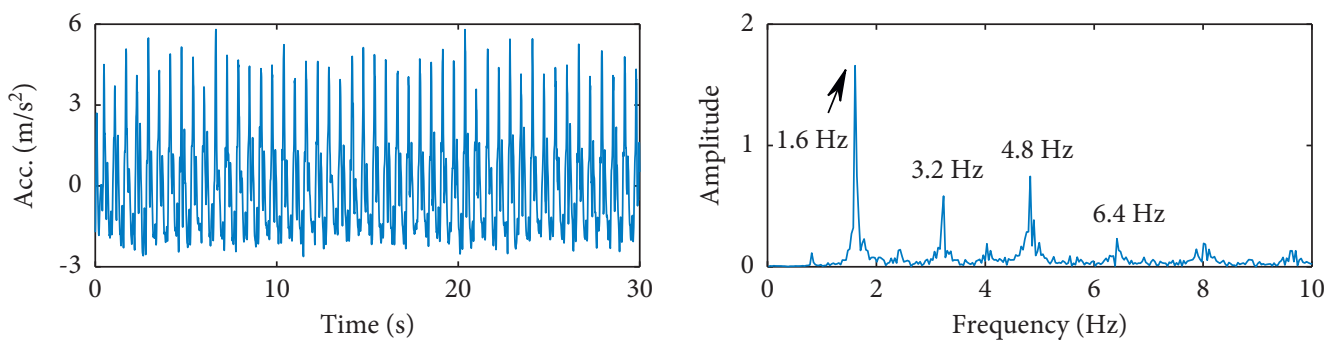

(a)
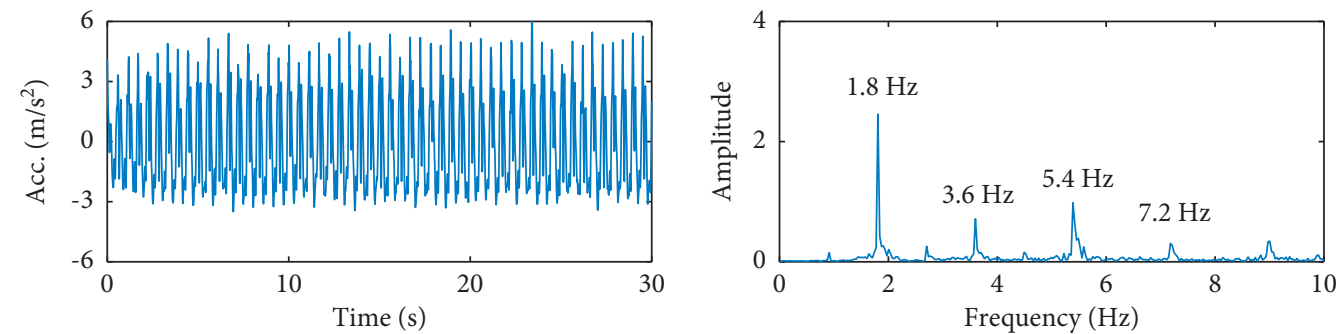

(b)
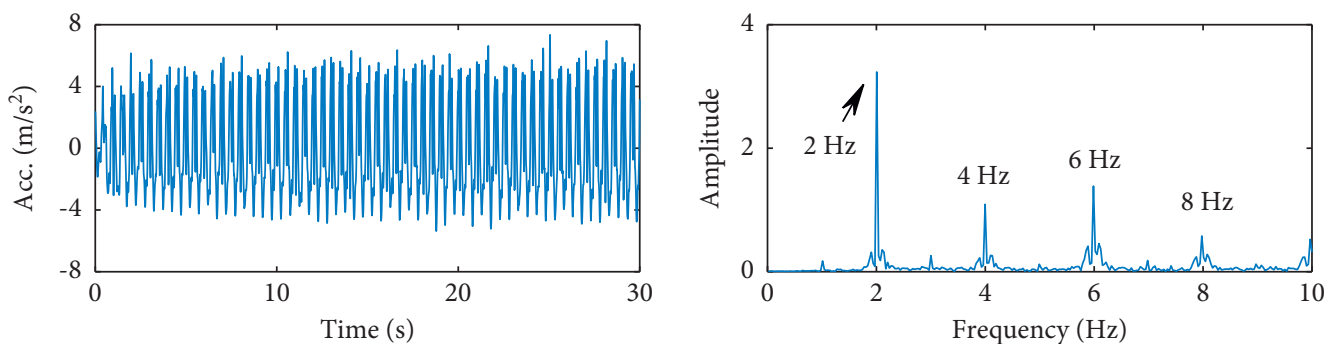

(c)
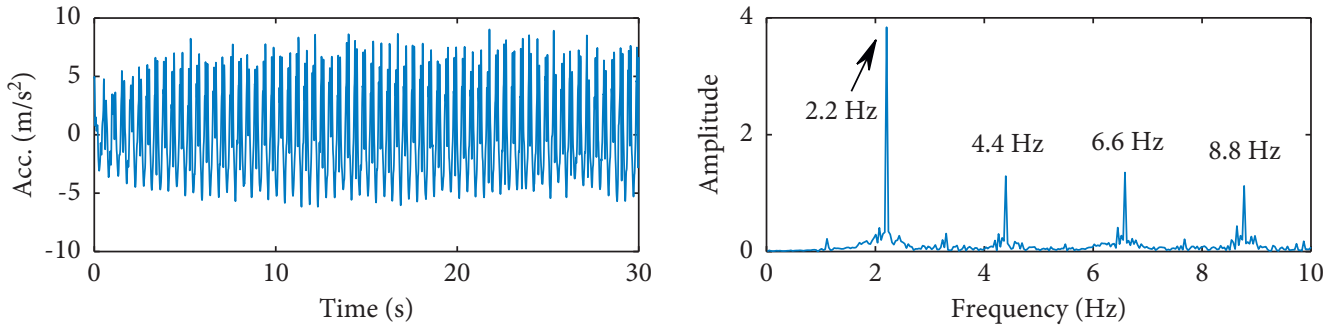

(d)
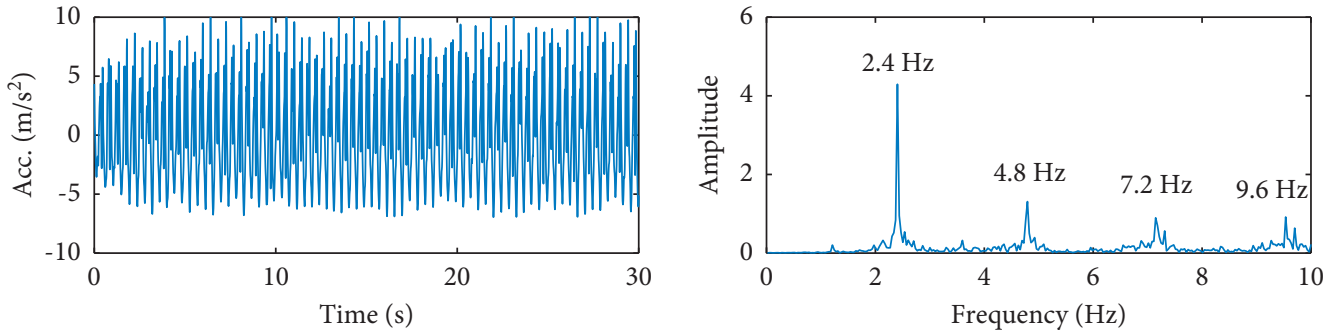

(e)

FIGURE 18: Vertical body acceleration for a single-person walking at step frequencies of (a) $1.6 \mathrm{~Hz}$, (b) $1.8 \mathrm{~Hz}$, (c) $2.0 \mathrm{~Hz}$, (d) $2.2 \mathrm{~Hz}$, and (e) $2.4 \mathrm{~Hz}$ in time and frequency domains. 


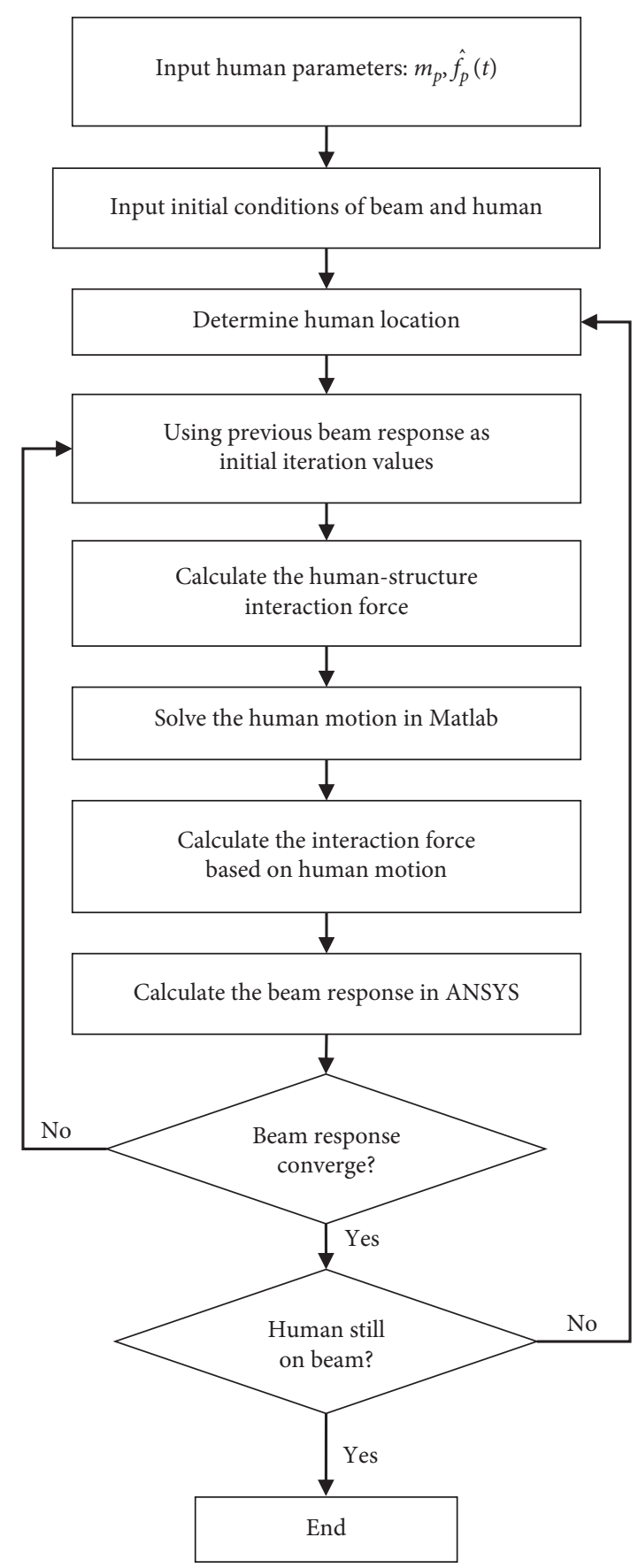

FIGURE 19: Solution procedure of the bridge-walking human coupled system. 


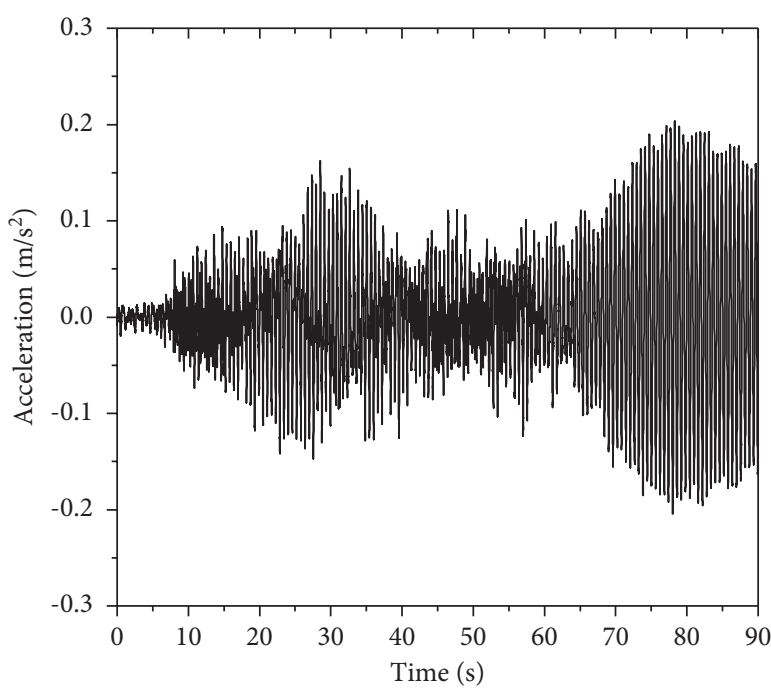

— simulated

(a)

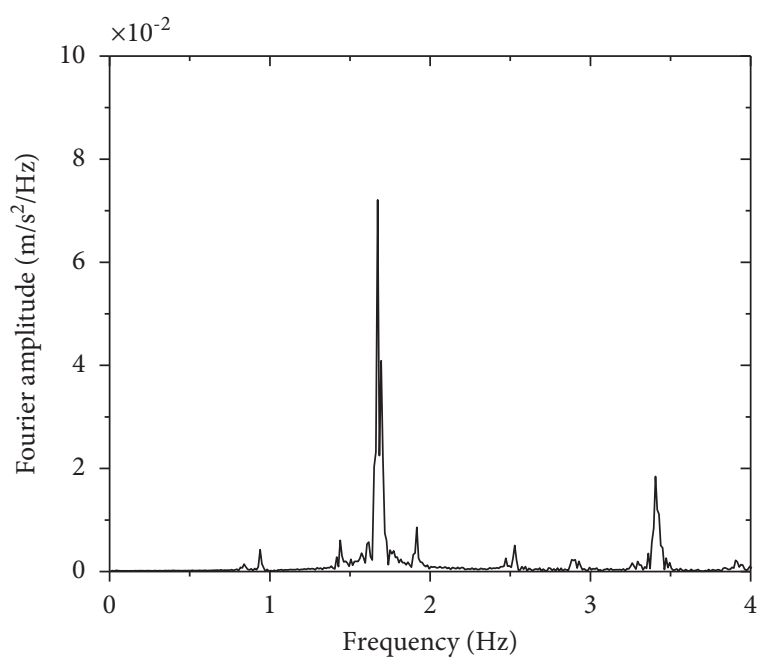

— Simulated

(c)

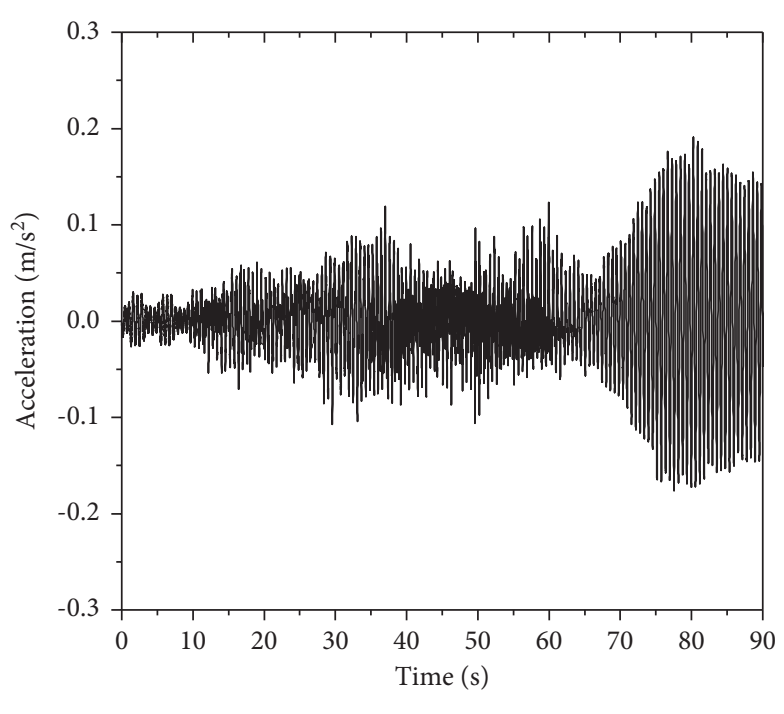

(b)

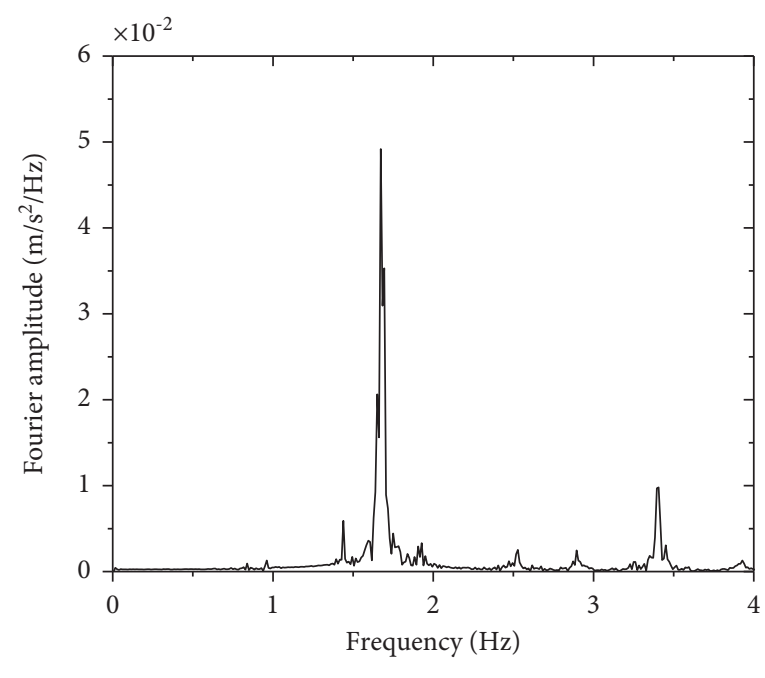

(d)

FIGURE 20: Comparison between simulated and measured bridge acceleration at the center of the main span: (a) simulated time history; (b) measured time history; (c) simulated spectrum; (d) measured spectrum. 


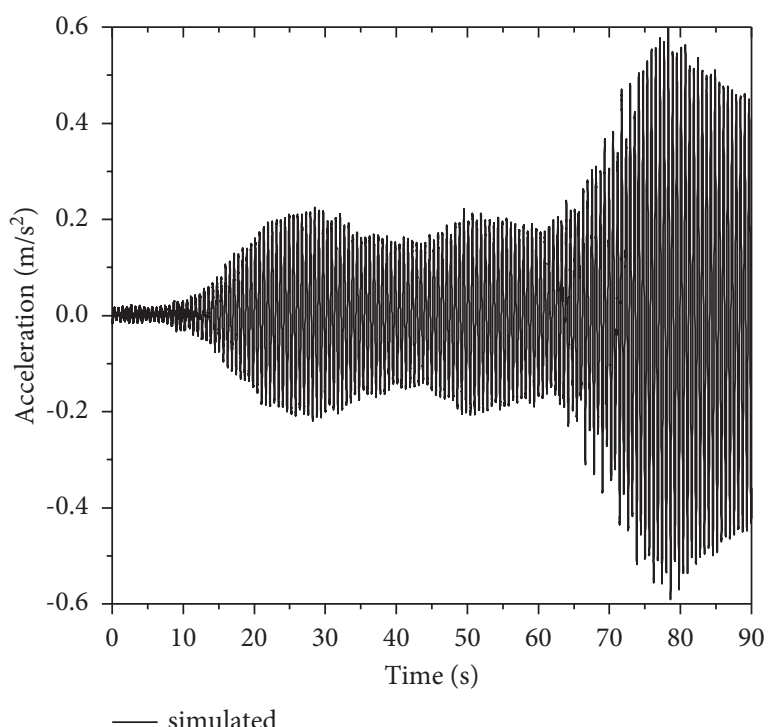

(a)

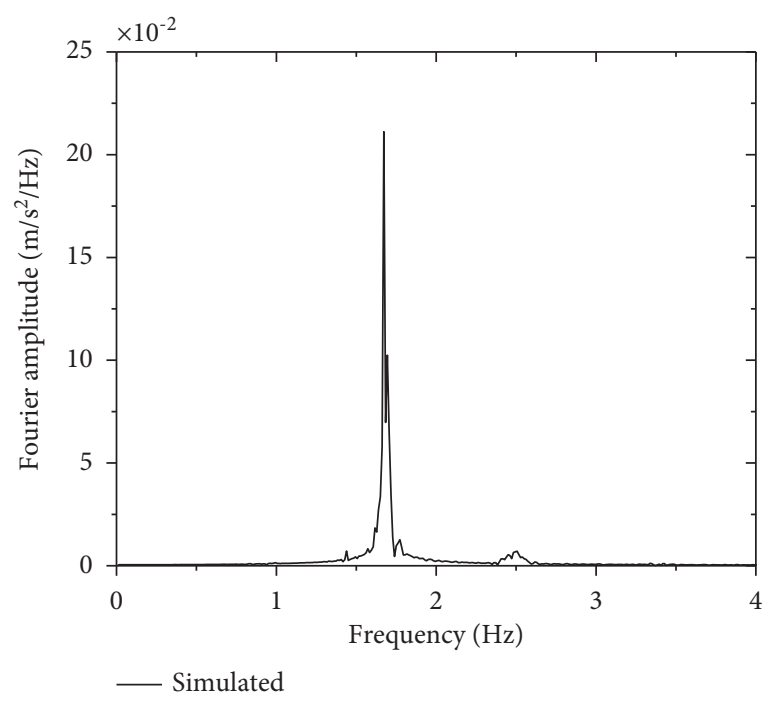

(c)

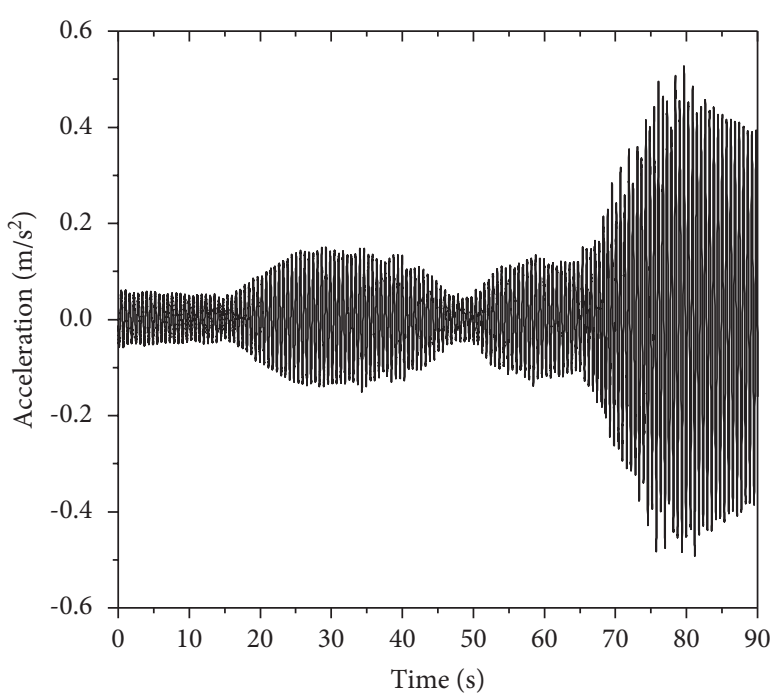

— Measured

(b)

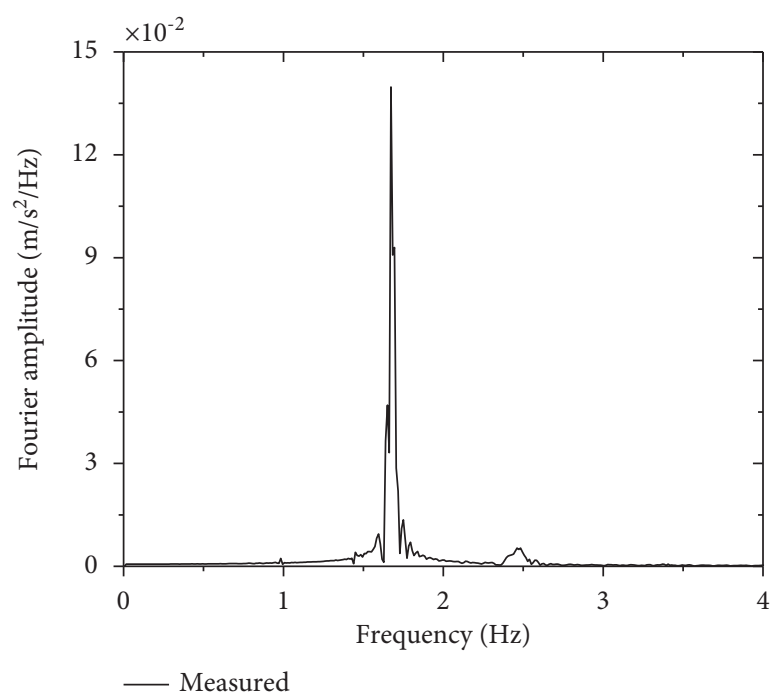

(d)

FIGURE 21: Comparison between simulated and measured bridge acceleration at the center of side span: (a) simulated time history; (b) measured time history; (c) simulated spectrum; (d) measured spectrum.

\section{Concluding Remarks}

This study has presented a flexible asymmetric stress-ribbon pedestrian bridge's modal properties and dynamic performance via both experimental and analytical methods. The following conclusions could be drawn:

(1) Modal test showed that the stress-ribbon footbridge has closely spaced modes, low natural frequencies, and small damping ratios $(<0.002)$. The measured first three natural frequencies are $0.95 \mathrm{~Hz}, 1.45 \mathrm{~Hz}$, and $1.68 \mathrm{~Hz}$, respectively. A numerical model that considers the pretension of the stress ribbon and contribution of deck panels is developed and proven capable of reflecting the main dynamic properties of the actual bridge.
(2) The maximum bridge acceleration reaches $2.14 \mathrm{~m} /$ $\mathrm{s}^{2}$ for small group synchronized walking; however, it reduces to $0.43 \mathrm{~m} / \mathrm{s}^{2}$ under random group walking.

(3) The bridge response is more sensitive to step frequency rather than the pedestrian number. Compared with single-person walking, the bridge response under multiple-person synchronized walking is not linearly amplified by pedestrian number.

(4) A theoretical model considering the human-structure interaction is developed by treating the single walking person as an SDOF system with biomechanical excited force. The validity of the model was verified by field measurement results. 
Further extensions of the present study may include mechanic property and its influence factors of the stressribbon bridge. Besides, mitigation measures against excessive bridge vibration should be considered in the future to improve the vibration serviceability of the footbridge.

\section{Data Availability}

Relevant data used in this paper can be accessed upon request to the corresponding author.

\section{Conflicts of Interest}

The authors declare that they have no conflicts of interest.

\section{Acknowledgments}

This work was supported by the National Natural Science Foundation of China (51508431) and the Fundamental Research Funds for the Central Universities (CUG190637).

\section{References}

[1] S. Zivanovic, A. Pavic, and P. Reynolds, "Vibration serviceability of footbridges under human-induced excitation: a literature review," Journal of Sound and Vibration, vol. 279, no. 1-2, pp. 1-74, 2005.

[2] S. Zivanovic, A. Pavic, and P. Reynolds, "Probability-based prediction of multi-mode vibration response to walking excitation," Engineering Structures, vol. 29, no. 6, pp. 942-954, 2007.

[3] J. M. W. Brownjohn, A. Pavic, and P. Omenzetter, "A spectral density approach for modelling continuous vertical forces on pedestrian structures due to walking," Canadian Journal of Civil Engineering, vol. 31, no. 1, pp. 65-77, 2004.

[4] F. Venuti and F. Tubino, "Human-induced loading and dynamic response of footbridges in the vertical direction due to restricted pedestrian traffic," Structure and Infrastructure Engineering, vol. 17, no. 10, pp. 1431-1445, 2021.

[5] C. C. Caprani, J. Keogh, P. Archbold, and P. Fanning, "Enhancement factors for the vertical response of footbridges subjected to stochastic crowd loading," Computers \& Structures, vol. 102-103, pp. 87-96, 2012.

[6] W. He, C. Zou, Y. Pang, and X. Wang, "Environmental noise and vibration characteristics of rubber-spring floating slab track," Environmental Science and Pollution Research, vol. 28, no. 11, Article ID 13671, 2021.

[7] L. Bruno and F. Venuti, "Crowd-structure interaction in footbridges: modelling, application to a real case-study and sensitivity analyses," Journal of Sound and Vibration, vol. 323, no. 1-2, pp. 475-493, 2009.

[8] W. He and W. P. Xie, "Characterization of stationary and walking people on vertical dynamic properties of a lively lightweight bridge," Structural Control and Health Monitoring, vol. 25, no. 3, p. e2123, 2018.

[9] F. Venuti, V. Racic, and A. Corbetta, "Modelling framework for dynamic interaction between multiple pedestrians and vertical vibrations of footbridges," Journal of Sound and Vibration, vol. 379, pp. 245-263, 2016.

[10] F. Ricciardelli and C. Demartino, "Design of footbridges against pedestrian-induced vibrations," Journal of Bridge Engineering, vol. 21, no. 8, Article ID C4015003, 2016.
[11] F. Venuti and A. Reggio, "Mitigation of human-induced vertical vibrations of footbridges through crowd flow control," Structural Control and Health Monitoring, vol. 25, no. 12, Article ID e2266, 2018.

[12] S. E. T. RA. Footbridge, Assessment of Vibrational Behaviour of Footbridge under Pedestrian Loading, Setra, Paris France, 2006.

[13] J. Chen, R. Xu, and M. Zhang, "Acceleration response spectrum for predicting floor vibration due to occupant walking," Journal of Sound and Vibration, vol. 333, no. 15, pp. 3564-3579, 2014.

[14] A. S. Mohammed, A. Pavic, and V. Racic, "Improved model for human induced vibrations of high-frequency floors," Engineering Structures, vol. 168, pp. 950-966, 2018.

[15] Z. O. Muhammad and P. Reynolds, "Vibration serviceability of building floors: performance evaluation of contemporary design guidelines," Journal of Performance of Constructed Facilities, vol. 33, no. 2, Article ID 04019012, 2019.

[16] B. M. Basaglia, J. Li, R. Shrestha, and K. Crews, "Response prediction to walking-Induced vibrations of a long-span timber floor," Journal of Structural Engineering, vol. 147, no. 2, Article ID 04020326, 2021.

[17] K. A. Salyards and L. M. Hanagan, "Evaluation of vibration assessment criteria and their application to stadium serviceability," Journal of Performance of Constructed Facilities, vol. 24, no. 2, pp. 100-107, 2010.

[18] N. T. Do, M. Gül, O. Abdeljaber, and O. Avci, "Novel framework for vibration serviceability assessment of stadium grandstands considering durations of vibrations," Journal of Structural Engineering, vol. 144, no. 2, Article ID 04017214, 2018.

[19] J. Strasky, Stress Ribbon and cable-supported Pedestrian Bridges, Thomas Telford, London England UK, 2005.

[20] R. Agrawal, "Stress ribbon bridges," Structural Engineer, vol. 87, no. 22, pp. 22-27, 2009.

[21] D. C. D. Arco, Á. C. Aparicio, and A. R. Maŕ, "Preliminary design of prestressed concrete stress ribbon bridge," Journal of Bridge Engineering, vol. 6, no. 4, pp. 234-242, 2001.

[22] G. Arndt, M. Schlaich, and M. Meiselbach, "Stress ribbon bridges: mechanics of the stress ribbon on the saddle," Journal of Bridge Engineering, vol. 21, no. 5, Article ID 04015089, 2016.

[23] W. H. Hu, E. Caetano, and Á. Cunha, "Structural health monitoring of a stress-ribbon footbridge," Engineering Structures, vol. 57, pp. 578-593, 2013.

[24] J. M. Soria, I. M. Díaz, H. Jaime, G. Palacios, and N. Ibán, "Vibration monitoring of a steel-plated stress-ribbon footbridge: uncertainties in the Modal Estimation," Journal of Bridge Engineering, vol. 21, no. 8, Article ID C5015002, 2016.

[25] S. S. Ivanovic, M. D. Trifunac, and M. I. Todorovska, "Ambient vibration test-a review," ISET Journal of Eearthquake Technology, vol. 37, no. 4, pp. 165-197, 2000.

[26] B. Jaishi and W. X. Ren, "Structural finite element model updating using ambient vibration test results," Journal of Structural Engineering, vol. 131, no. 4, pp. 617-628, 2005.

[27] B. Peeters and G. D. Roeck, "Reference-based stochastic subspace identification for output-only modal analysis," Mechanical Systems and Signal Processing, vol. 13, no. 6, pp. 855-878, 1999.

[28] W. X. Ren, X. L. Peng, and Y. Q. Lin, "Experimental and analytical studies on dynamic characteristics of a large span cable-stayed bridge," Engineering Structures, vol. 27, no. 4, pp. 535-548, 2005.

[29] P. V. Overschee and D. B. Moor, Subspace Identification for Linear System: Theory-Implementation-Applications, Kluwer 
Academic Publishers, Alphen aan den Rijn, Netherlands, 1996.

[30] F. Magalhãs, E. Caetano, Á Cunha, O. Flamand, and G. Grillaud, "Ambient and free vibration tests of the Millau Viaduct: evaluation of alternative processing strategies," Engineering Structures, vol. 45, pp. 372-384, 2012.

[31] F. L. Huang, X. H. He, and Z. Q. Chen, "A new approach for identification of modal damping ratios for a structure," China Civil Engineering Journal, vol. 35, no. 6, pp. 20-24, 2002, (in Chinese).

[32] Bases for Design of Structures-Serviceability of Buildings and Walkways against Vibrations, ISO (International Organization for Standardization), Geneva, Switzerland, 2007.

[33] M. S. Zhang, C. T. Georgakis, and J. Chen, "Biomechanically excited SMD model of a walking pedestrian," Journal of Bridge Engineering, vol. 21, no. 8, Article ID C4016003, 2016.

[34] J. M. W. Brownjohn, J. Chen, M. Bocian, V. Racic, and E. Shahabpoor, "Using inertial measurement units to identify medio-lateral ground reaction forces due to walking and swaying," Journal of Sound and Vibration, vol. 426, pp. 90110, 2018.

[35] Z. Han, J. M. W. Brownjohn, and J. Chen, "Structural modal testing using a human actuator," Engineering Structures, vol. 221, Article ID 111113, 2020. 